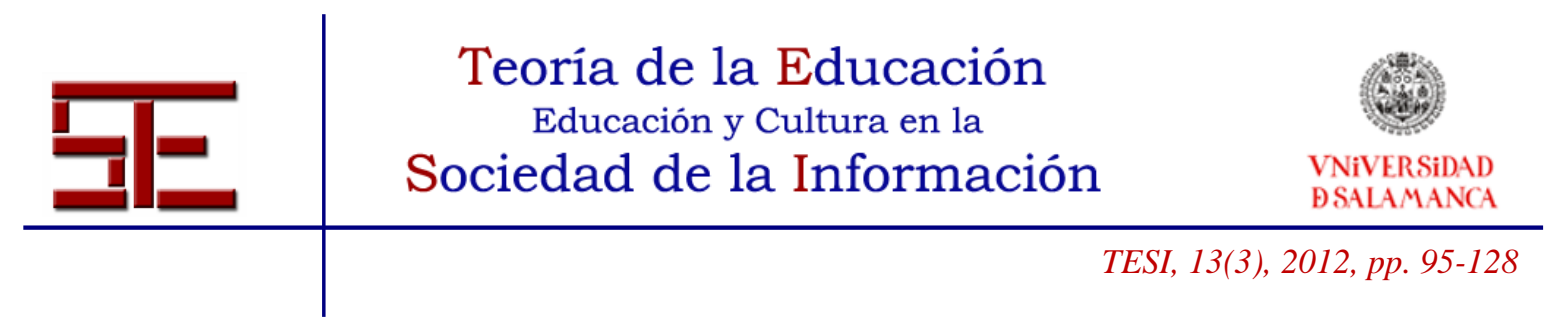

\title{
EL MODELO DEL RENDIMIENTO ACADÉMICO DEL ESTUDIANTE UNIVERSITARIO: APLICACIÓN A UNA FACULTAD DE ECONOMÍA
}

Resumen: El presente estudio persigue avanzar sobre el conocimiento del rendimiento académico del estudiante. Concretamente, y siguiendo la propuesta de Fenollar, Cuestas y Román (2006), se plantea un modelo integrador de las teorías que explican el rendimiento académico del estudiante; entendido éste como el aprendizaje percibido y la nota esperada por el estudiante. En concreto, aquellas basadas en la Teoría CognitivaLogro iniciada por Deck (1986) y la Teoría de la Autoeficiencia desarrollada por Bandura (1986). Se analiza el efecto que estas teorías poseen en (1) el aprendizaje percibido por el estudiante, (2) la nota esperada y (3) la satisfacción global del estudiante. Así, se llevó a cabo un estudio con 932 estudiantes de una Facultad de Economía. Los resultados ponen de manifiesto la importancia de la autoeficiencia y de ciertas orientaciones sobre el rendimiento de estudiante; así como de éste sobre su satisfacción.

Palabras clave: orientaciones del estudiante; autoeficiencia; rendimiento del estudiante; Facultad de Economía.

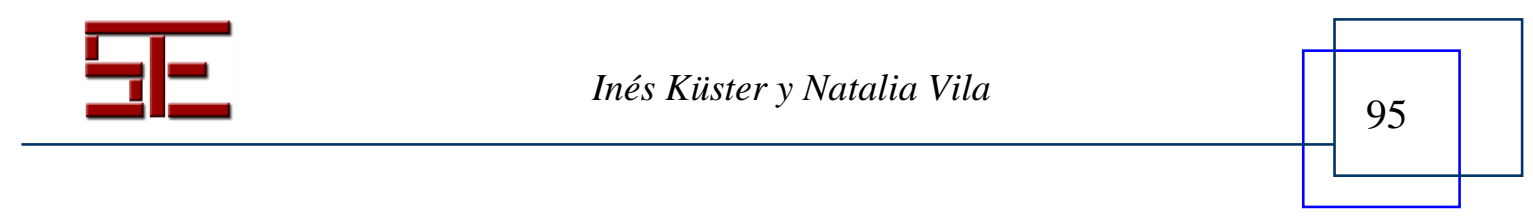




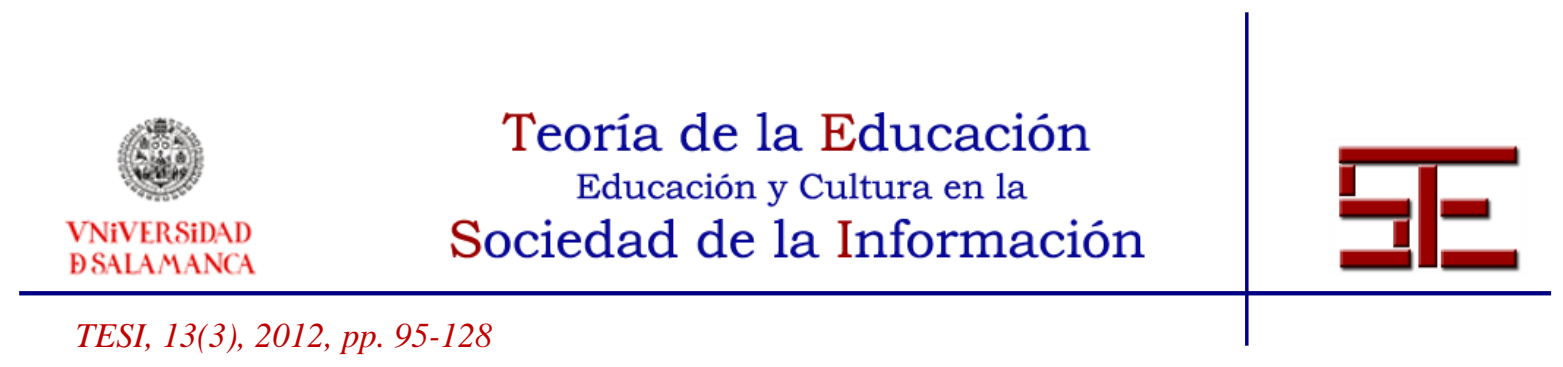

\title{
UNIVERSITY STUDENTS' ACADEMIC PERFORMANCE: AN APPLICATION IN A FACULTY OF ECONOMICS
}

\begin{abstract}
This study aims to advance knowledge about student academic performance. Specifically, following the proposal of Fenollar, Cuestas and Roman (2006), we propose an integrative model of theories that explain the student's academic performance, understood as the perceived learning and the student note expected. In particular, those based on Cognitive Achievement Theory initiated by Deck (1986) and Self-efficacy Theory developed by Bandura (1986). We analyze the effect that these theories have in (1) learning perceived by the student, (2) the expected note and (3) overall student satisfaction. Thus, we conducted a study with 932 students of a Faculty of Economics. The results highlight the importance of self-efficacy and some orientations on student performance, as well as this one on his satisfaction.
\end{abstract}

Keywords: students' orientations; self-eficacy; student academic performance; Faculty of Economy

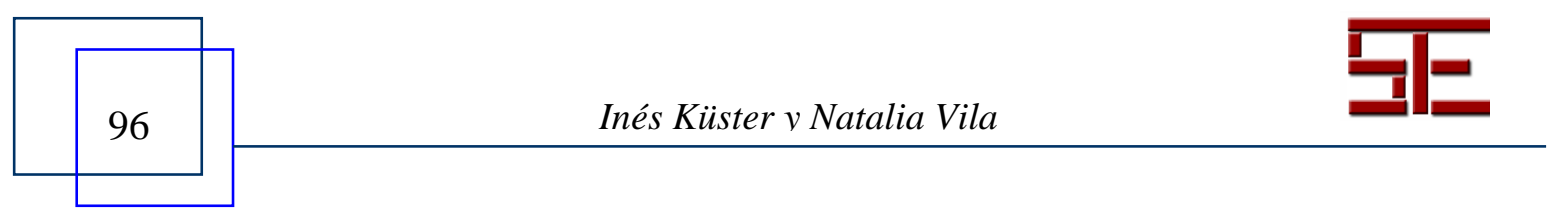




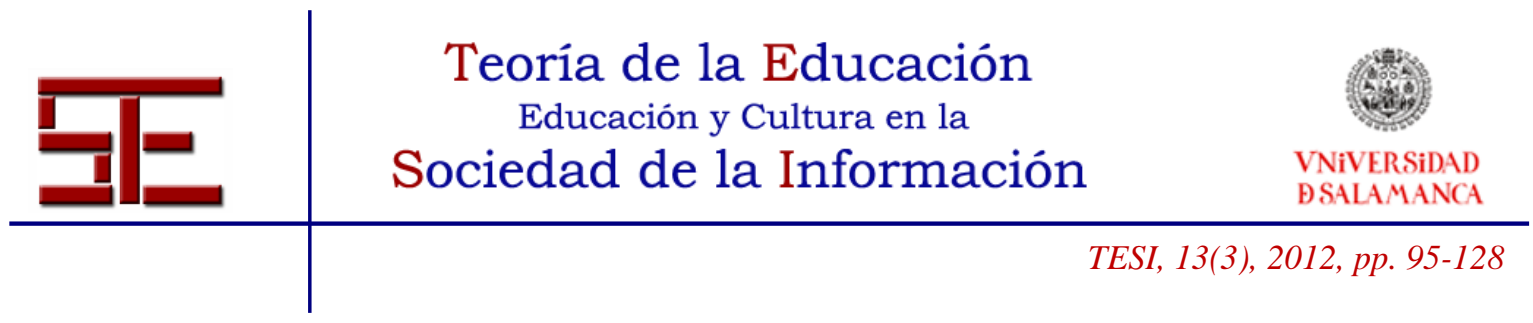

\section{EL MODELO DEL RENDIMIENTO ACADÉMICO DEL ESTUDIANTE UNIVERSITARIO: APLICACIÓN A UNA FACULTAD DE ECONOMÍA}

Fecha de recepción: 18/04/2012; fecha de aceptación: 07/07/2012; fecha de publicación: 30/11/2012

Inés Küster

ines.kuster@uv.es

Universidad de Valencia

Natalia Vila

natalia.vila@uv.es

Universidad de Valencia

\section{INTRODUCCIÓN}

Adams (1998) afirma que el efecto y la aceleración de los cambios producidos en la educación superior han propiciado que académicos y gobiernos investiguen sobre los mismos. Dichos cambios han variado en cuanto a su naturaleza e intensidad, pero todos ellos destacan y/o recaen sobre la figura del docente como eje central del proceso enseñanza-aprendizaje.

Que duda cabe que la universidad lleva a cabo su labor de enseñanza, formación e investigación en interacción continua con su entorno social, teniendo que adaptarse a las necesidades y cambios de éste y mejorando la calidad de sus prestaciones (García y Fernández, 2002). Así, García y Fernández (2002) describen la transformación de la función de la universidad como un proceso continuo de cambio paralelo a los cambios políticos, económicos y del mundo laboral, lo que ha ocasionado que tenga "notables problemas estructurales, con serias dificultades para atender el número de personas que acceden a ella y con una clara separación de la sociedad" (p. 77). Por su lado, Petruzzellis, D’Uggento y Romanazzi (1996) establecen que las universidades se enfrentan a una intensa competencia nacional e internacional. Comparten con Tiebout (1956) la idea de que, de hecho, los consumidores o, más bien, la sociedad, juega un papel activo en la definición de la oferta, ya sea solicitando cursos por medio de la inscripción o mostrando su desaprobación abandonando la universidad.

En este marco, y como afirman Flavián y Lozano (2004), la universidad pública española ha experimentado durante los últimos años profundas transformaciones que

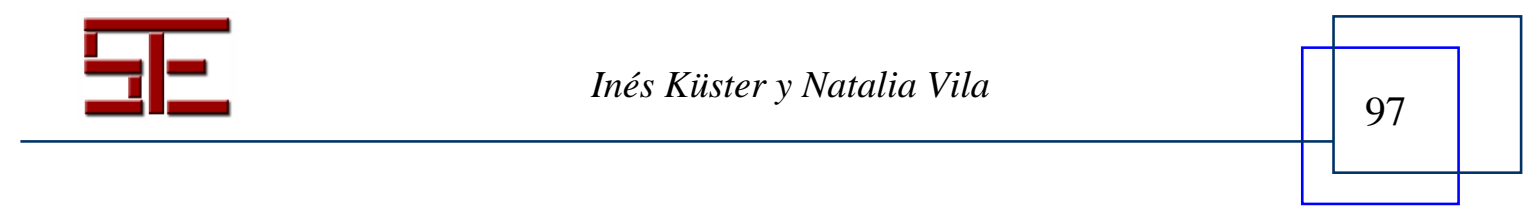




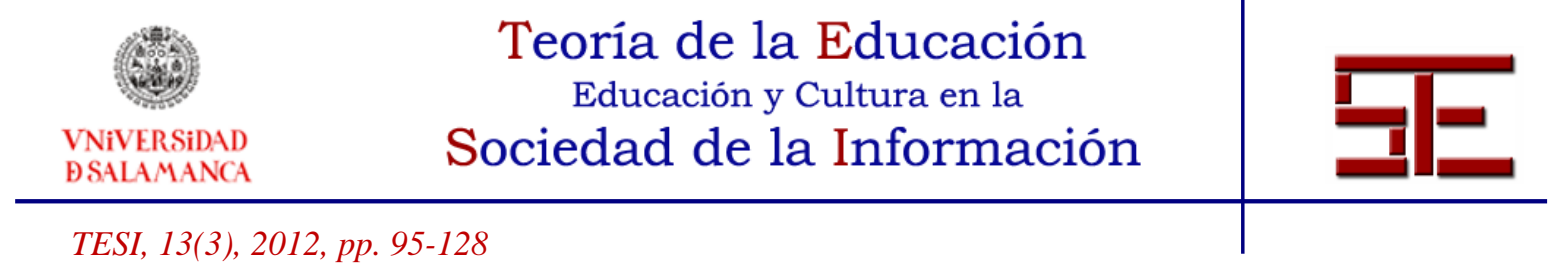

están motivando cambios importantes respecto al grado de rivalidad soportada, el tipo de actividades desarrolladas y la forma a través de la cual éstas son llevadas a cabo. Junto a los factores mencionados, los autores añaden lo que supone el actual período de transición en el que se encuentra inmerso el sistema universitario como consecuencia de la entrada en vigor de la Ley Orgánica de Universidades, de 21 de diciembre de 2001 (BOE de 24 de diciembre), así como el cercano horizonte de puesta en funcionamiento real del Espacio Europeo de Educación Superior, que plantea la necesidad de afrontar retos de una notable trascendencia para el panorama educativo español, así como para el de los demás países del entorno comunitario (Flavián y Lozano, 2004). Junto a ello, y con la entrada en vigor del Real Decreto 1393/2007, de 29 de octubre (BOE de 30 de octubre), por el que se establece la ordenación de las enseñanzas universitarias oficiales, se impulsa un cambio en las metodologías docentes, y se centra su objetivo en el proceso de aprendizaje del estudiante, en un contexto que se extiende ahora a lo largo de la vida.

Por ello, el interés de la presente investigación intenta avanzar en el conocimiento acerca del rendimiento académico del estudiante. En este sentido, y de acuerdo con Fenollar, Cuestas y Román (2006), los trabajos previos que han analizado los antecedentes del rendimiento académico de los estudiantes han sido numerosos, pero el debate continúa siendo un tema de actualidad. Por lo tanto, se ha tratado de explicar el rendimiento académico del estudiante a partir de variables relativas al propio estudiante. Concretamente, y siguiendo la propuesta de Fenollar, Cuestas y Román (2006), se plantea un modelo integrador de las teorías que explican el rendimiento académico del estudiante; entendido éste como el aprendizaje percibido y la nota esperada por el estudiante. En concreto, aquellas basadas en la Teoría Cognitiva-Logro iniciada por Deck (1986) y la Teoría de la Autoeficiencia desarrollada por Bandura (1986). Se analiza el efecto que estas teorías poseen en (1) el aprendizaje percibido por el estudiante, (2) la nota esperada y (3) la satisfacción global del estudiante.

A fin de alcanzar los objetivos descritos, se plantea una investigación entre los estudiantes de una Facultad de Economía. La importancia de esta investigación puede sintetizarse en el avance en la comprensión del rendimiento del estudiante universitario en términos de antecedentes y consecuencias. Para ello, el trabajo se estructura como sigue. En primer lugar, se define el concepto de rendimiento académico del estudiante, comentando las teorías sobre las que se asienta la presente investigación. Todo ello conduce al planteamiento de las hipótesis de trabajo en un epígrafe posterior. A

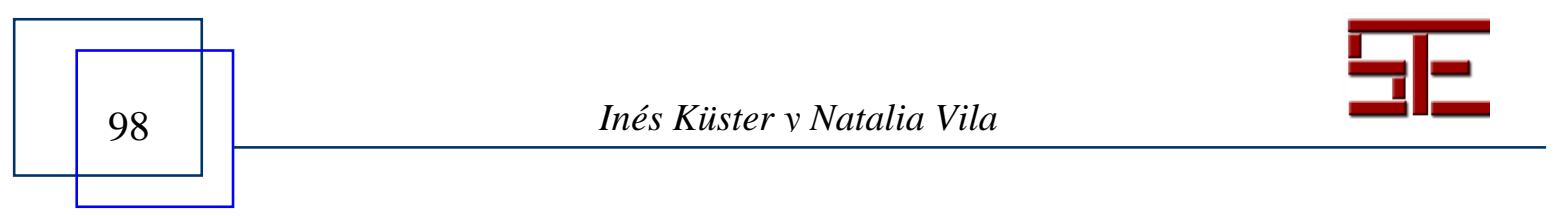




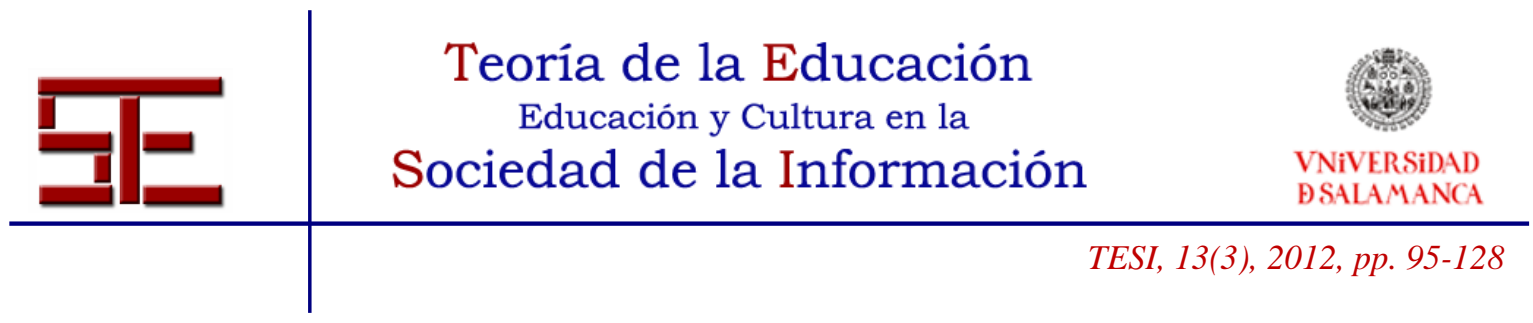

continuación, se establece la metodología empleada para el contraste empírico de las hipótesis, y posteriormente se detalla el análisis e interpretación de los resultados obtenidos. Se concluye con la exposición de las implicaciones que tienen dichos resultados en las instituciones universitarias, además de indicar las limitaciones del estudio y las posibles líneas de investigación.

\section{EL PAPEL DEL ESTUDIANTE UNIVERSITARIO EN EL MODELO DEL RENDIMIENTO}

Tal y como se ha indicado, docente y estudiante son dos piezas angulares en el proceso de enseñanza-aprendizaje, convirtiéndose en dos elementos clave del sistema educativo de enseñanza superior. En este marco, se defiende que la preocupación última de los docentes y de las instituciones en las que éstos trabajan debería ser la satisfacción de sus clientes. Ahora bien, la delimitación del cliente del sistema universitario no resulta sencilla (Flavián y Lozano, 2005), pues, junto a los estudiantes, la sociedad o las empresas representan otros públicos de interés. Sin embargo, entendemos que los estudiantes se convierten en los primeros clientes o clientes más directos con los que el docente establece relación; son los receptores formativos del docente.

La justificación podría encontrarse en que, y de acuerdo con Tejero y García-Valcárcel (2007), las investigaciones llevadas a cabo permiten concluir que en todos los países de nuestro entorno económico-cultural existe el problema del bajo rendimiento en el sistema universitario, tanto si se mide el rendimiento a través de las tasas de abandonoéxito, como si se mide mediante la regularidad académica o de las calificaciones obtenidas.

Entre los factores que influyen en el rendimiento académico del estudiante, se pueden diferenciar tres aspectos clave: (1) los inherentes al alumno, (2) los inherentes al docente y (3) los inherentes a la organización académica universitaria. En este sentido, el presente estudio analiza aquellos antecedentes clave del rendimiento académico del estudiante, relativos a sus orientaciones/motivaciones y su autoeficacia.

De acuerdo con Edel (2003) y Tejero y García-Valcárcel (2007), el análisis sobre el rendimiento académico muestra una gran diversidad de líneas de estudio, lo que permite no sólo comprender su complejidad, sino su importancia dentro del campo educativo.

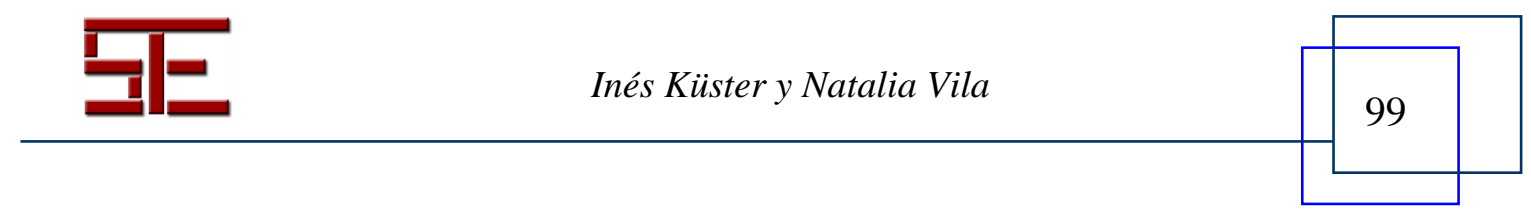




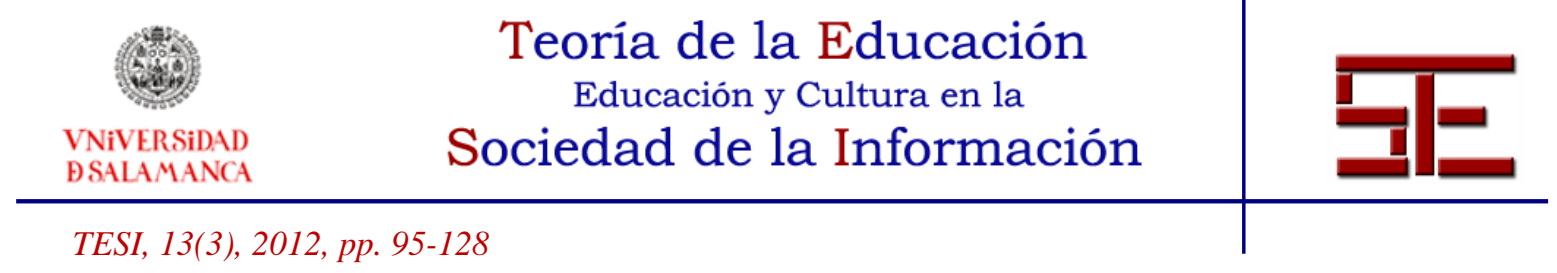

En el presente trabajo defendemos la propuesta de Fenollar, Román y Cuestas (2008) quienes consideran "el rendimiento académico más allá de la tradicional calificación o nota, extendiéndolo a otras variables cualitativas tales como el aprendizaje percibido y la nota esperada" (p. 9). Así, el aprendizaje percibido se refiere a una evaluación subjetiva realizada por el estudiante acerca del incremento en su conocimiento declarativo (conocer hechos o definiciones) y procedimental (saber cómo completar una determinada tarea) relacionado con la asignatura (Marks, 2000). Por su parte, la nota esperada, se relaciona con las expectativas del alumno sobre la nota que piensa obtener en la asignatura (Fenollar; Román y Cuestas, 2005). Por tanto, el rendimiento académico del estudiante se puede aproximar desde un punto de vista cualitativo a partir de estas dos variables: la nota esperada y el aprendizaje percibido.

Del mismo modo, en la actualidad existen diversas investigaciones que se dirigen a encontrar explicaciones del rendimiento académico de los estudiantes; desde estudios exploratorios, descriptivos y correlacionales hasta estudios explicativos (Edel, 2003; Caballero, 2006). En la presente investigación, se pretende replicar y ampliar el modelo de rendimiento académico propuesto por Fenollar, Román y Cuestas (2008). En este sentido, se acude a la Teoría Cognitiva de la Motivación-Logro y a la Teoría de la Autoeficacia para explicar el rendimiento académico de los estudiantes.

Así, la Teoría Cognitiva de la Motivación-Logro, que tiene sus orígenes en el trabajo de Dweck (1986), parte de la premisa de que el comportamiento del estudiante está condicionado por el deseo de alcanzar unos objetivos particulares. De acuerdo con Fenollar, Román y Cuestas (2007 y 2008), los trabajos que han considerado este marco teórico se han centrado en dos motivaciones u orientaciones: (1) orientación al aprendizaje (learning, mastery or task oriented goals) y (2) orientación al resultado (performance or ego-oriented goals). La primera se enfoca hacia el incremento de la propia competencia (aprender) y la segunda hacia la ejecución (quedar bien ante los otros, o su vertiente de evitación: miedo al fracaso). La búsqueda de una u otra hace que el modo de afrontar las tareas varíe claramente (Cattaneo, Huertas y De la Cruz, 2004). Los individuos con motivaciones/orientaciones al aprendizaje tienden a utilizar atribuciones internas; mientras que los individuos con motivaciones/orientaciones de ejecución/al rendimiento, atribuciones externas. El predominio de una u otra meta de aprendizaje influye en las formas de pensar y actuar cuando se resuelve una tarea (Schiefele, 1991) y de enfrentarse y digerir el fracaso. Los que buscan aprender suelen interpretar el fracaso como un mero error, en cambio, los que buscan quedar bien

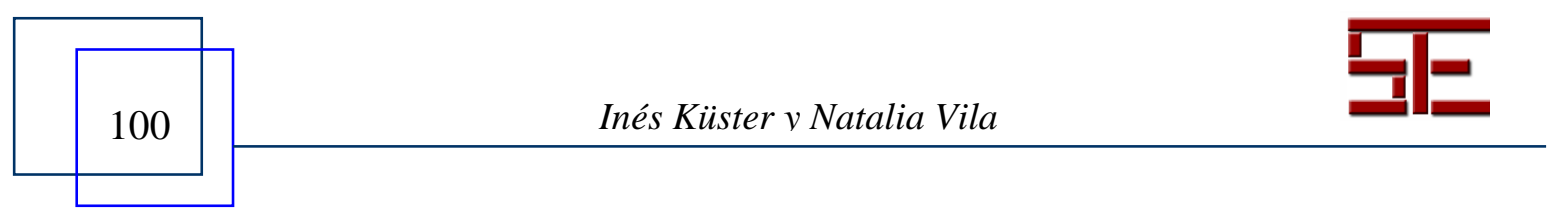




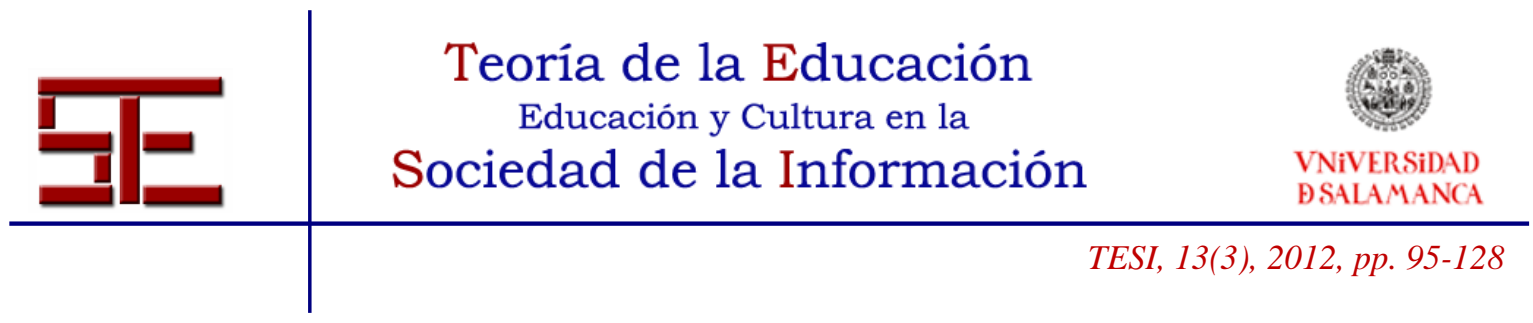

interpretan un fallo en la realización de una tarea como fracaso personal (Cattaneo, Huertas y De la Cruz, 2004).

Por otra parte, además de las motivaciones anteriores, otros investigadores han defendido la necesidad de considerar una tercera motivación adicional: la motivación a evitar tareas (work avoidance goals). Esta orientación se entiende como otra variable capaz de explicar parte del rendimiento académico del alumno (Seifert \& O'Keefe, 2001). Podría definirse como la preocupación por evitar llevar a cabo tareas desafiantes; reduciendo las tareas a realizar en la escuela (Seifert \& O'Keefe, 2001); esto es realizar el trabajo (o tarea) con el menor esfuerzo posible. Pese a la existencia de cierta evidencia de esta orientación, en comparación con las orientaciones al aprendizaje y a los resultados, aún hoy son relativamente escasos los trabajos que han tratado de analizar la orientación a evitar tareas (Seifert \& O’Keefe, 2001).

En suma, desde un enfoque motivacional, existen tres tipos de orientaciones que pueden influir sobre el rendimiento del estudiante: orientación al aprendizaje, orientación a los resultados y orientación a evitar tareas.

Junto al enfoque motivacional, la Teoría de la Autoeficacia, abanderada por Bandura (1986), defiende que la percepción que el estudiante tiene de sí mismo, en cuanto a su capacidad para llevar a cabo de forma exitosa las acciones necesarias para la obtención de una meta deseada, está relacionada con el rendimiento académico (p. e., Pajares \& Kranzler, 1995; Pajares, Hartley \& Valiante, 2001; Greene, Miller, Crowson, Duke \& Akey, 2004; Usher \& Pajares, 2006). Asimismo, aquellos estudiantes que se sienten competentes no sólo se orientan a posibles éxitos académicos, sino también al aprendizaje y al rendimiento (Elliot \& Church, 1997).

Así, y siguiendo el trabajo de Fenollar, Román y Cuestas (2008), replicamos y ampliamos su modelo propuesto en el que se integran las dos teorías mencionadas anteriormente como antecedentes del rendimiento académico del estudiante universitario; la teoría motivacional y la teoría de la autoeficacia. A diferencia de los autores, ampliamos el campo de estudio no únicamente a los estudiantes universitarios de marketing, sino a cualquier estudiante de una Facultad de Economía e incluimos una variable adicional, la satisfacción global del estudiante. A través de este modelo, será posible comprobar si el efecto de la autoeficacia sobre el rendimiento académico es directo o mediado a partir de las orientaciones/motivaciones (o incluso ambos). Cabe

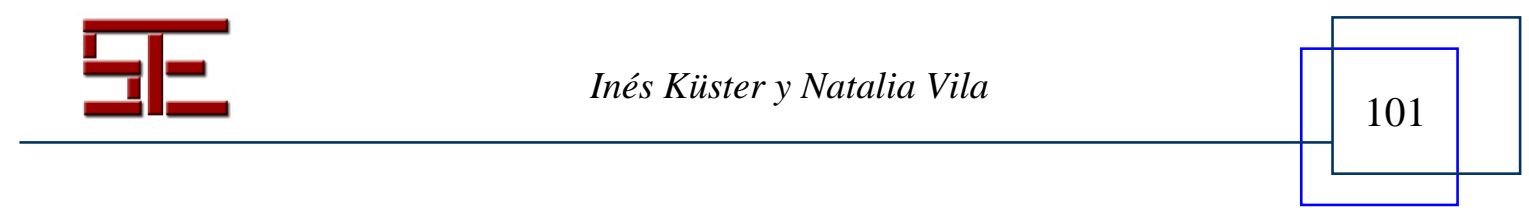




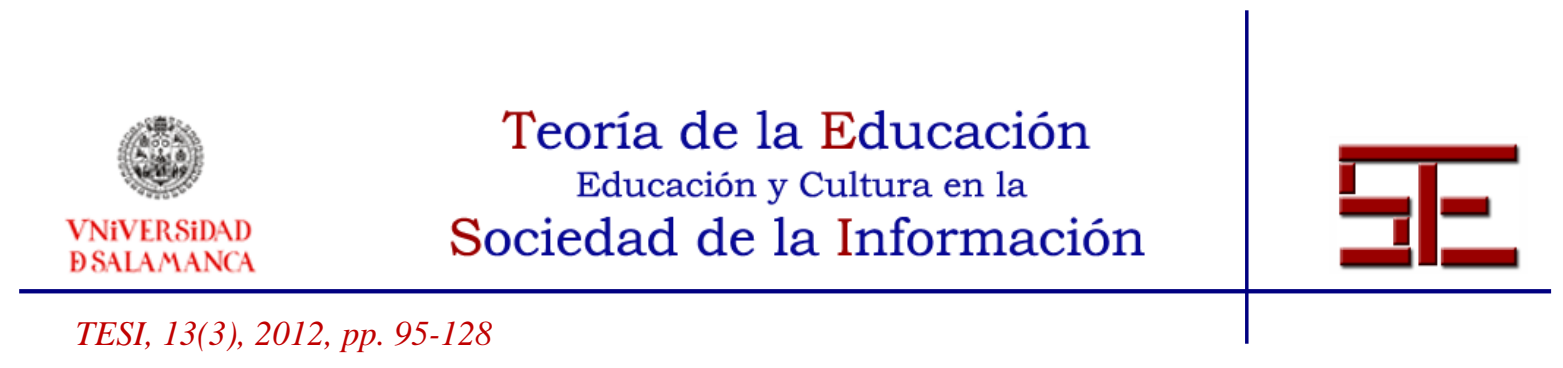

señalar que el desarrollo teórico del modelo propuesto por estos autores se nutre de estudios provenientes de diversas áreas de conocimiento, en concreto de la sociología, de la psicología educacional y del marketing. Adicionalmente, y al igual que los autores, se realiza el estudio en un contexto universitario. Esto último es particularmente relevante pues la mayoría de las investigaciones anteriores se han desarrollado sobre estudiantes de educación primaria o secundaria. En este sentido, algunos investigadores han señalado que las motivaciones y los estilos de aprendizaje de los alumnos universitarios difieren en gran medida de las de los alumnos de niveles educativos inferiores (Vermetten; Lodewijks \& Vermunt, 2001; Valle; Cabanach; Núnez; González-Pienda; Rodríguez \& Piñeiro, 2003).

La Figura 1 sintetiza el modelo propuesto. Siguiendo el orden de las hipótesis, el primer grupo se refiere al papel de la autoeficacia en el rendimiento académico, ya sea de forma indirecta a través de las orientaciones ( $\mathrm{H} 1 \mathrm{a}$ a $\mathrm{H} 1 \mathrm{c})$, o de forma directa $(\mathrm{H} 2 \mathrm{a}$ y $\mathrm{H} 2 b)$. Un segundo grupo (H3 a H5) recoge el efecto directo de las orientaciones (al aprendizaje, al rendimiento y a evitar tareas) sobre el rendimiento académico (el aprendizaje percibido y la nota esperada). Un tercer grupo (H6) propone un efecto del aprendizaje percibido sobre la nota esperada Finalmente, $\mathrm{H} 7 \mathrm{a}$ y b relacionan el efecto del rendimiento académico sobre la satisfacción global del estudiante.

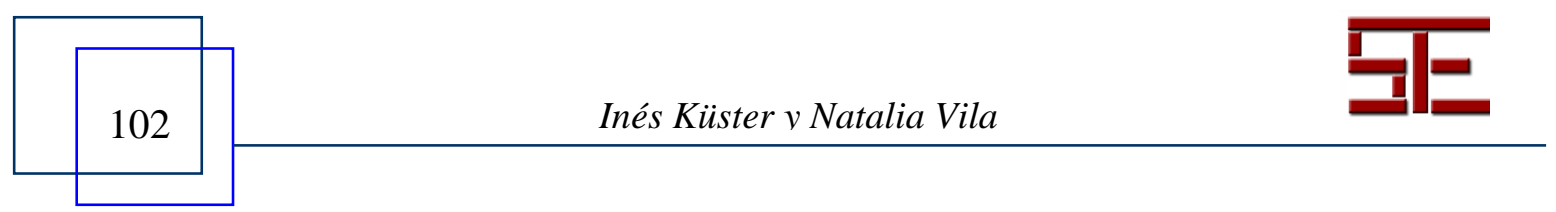




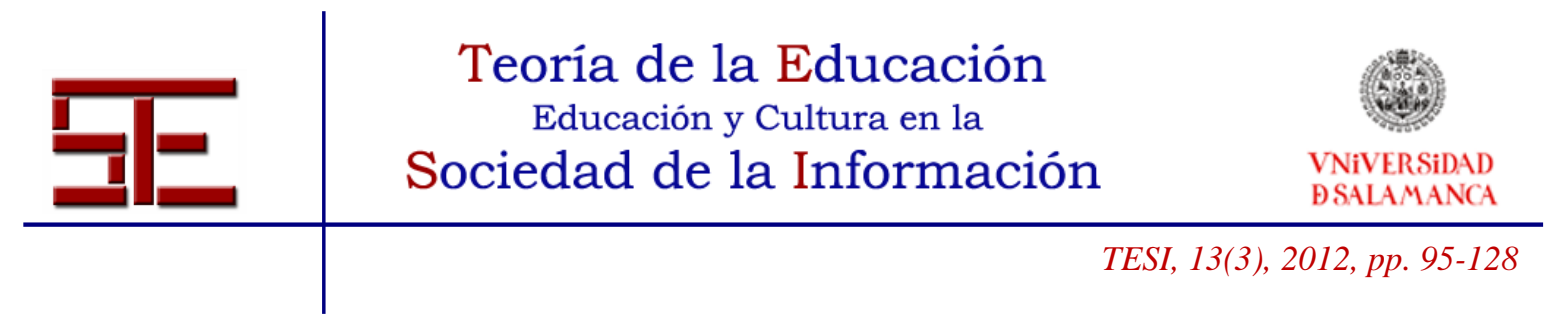

Figura 1. Modelo conceptual de rendimiento académico del estudiante

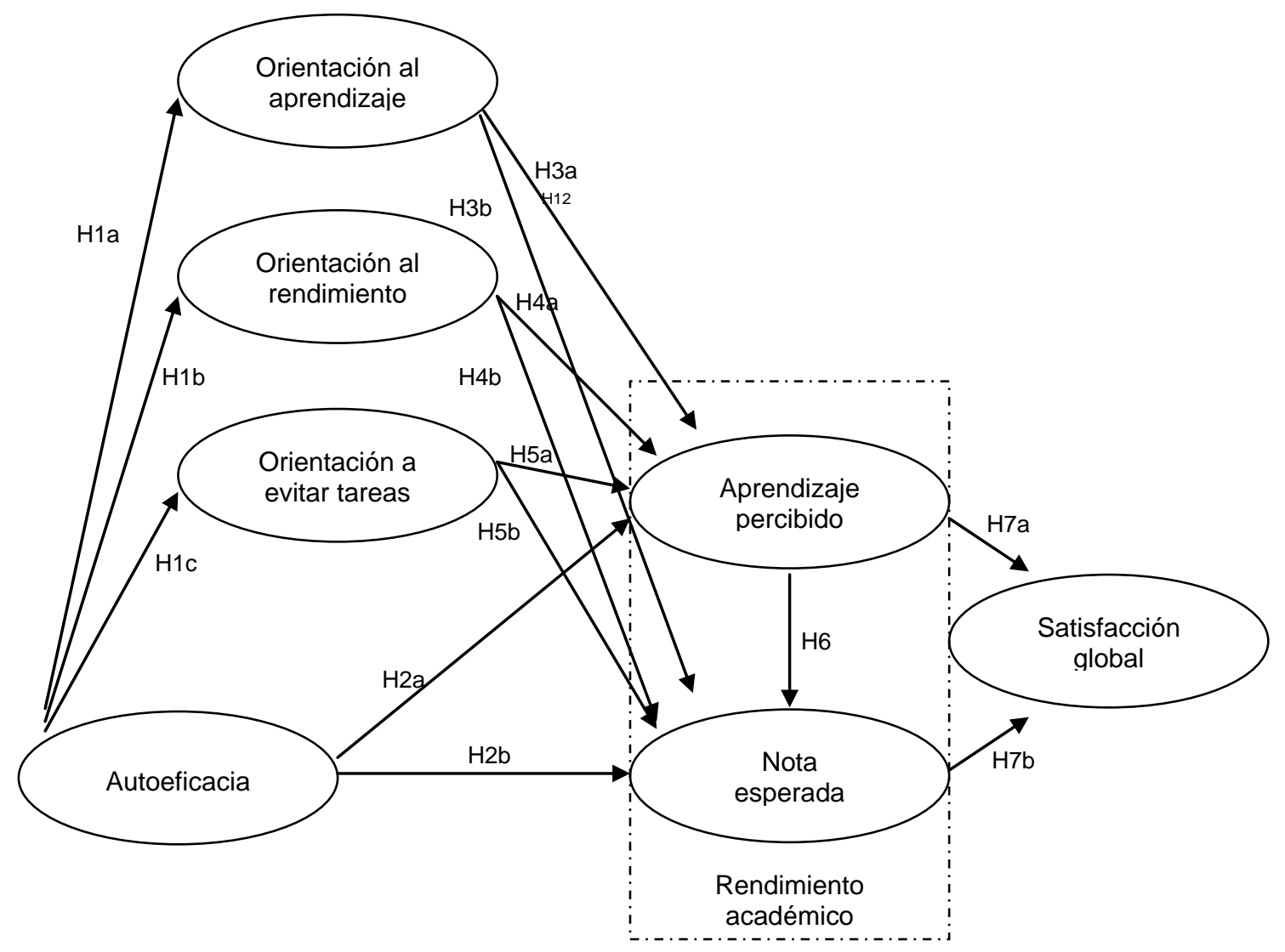

Fuente: A partir de Fenollar, Román y Cuestas (2008).

\subsection{La autoeficacia y sus efectos}

Con relación al primer grupo de hipótesis, y de acuerdo con Caballero (2006), la percepción de los estudiantes acerca de su propia autoeficacia se convierte en un requisito fundamental para desarrollar con éxito las acciones conducentes al logro de los objetivos personales. Dicha percepción ejerce una profunda influencia en la elección de tareas y actividades, en el esfuerzo y perseverancia de las personas cuando enfrentan determinados retos e incluso en las reacciones emocionales que experimentan ante situaciones difíciles (Prieto Navarro, 2001).

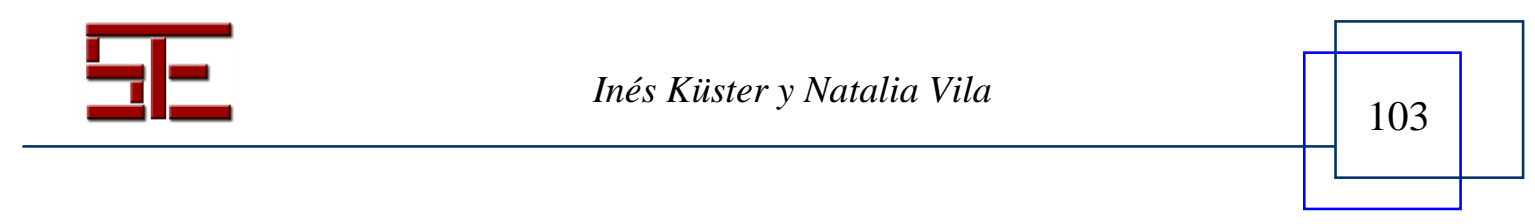




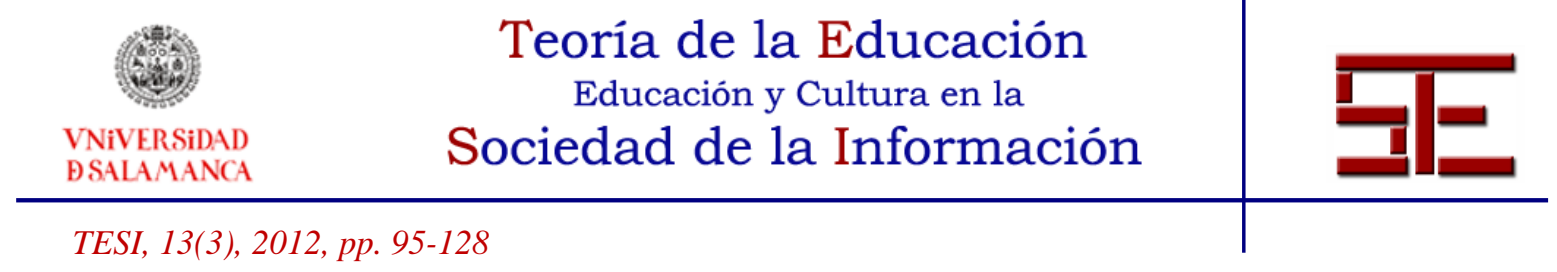

Como consecuencia, la autoeficacia se ha asociado frecuentemente con el rendimiento académico, destacándose su rol mediador cognitivo entre otros determinantes de las competencias (tales como habilidades, intereses y logros de ejecución anterior) y del rendimiento académico (Pajares, 1996). De este modo, los estudiantes que se perciben más autoeficaces persisten durante mayor tiempo cuando deben resolver problemas de difícil solución (Olaz, 2001).

De acuerdo con Usher y Pajares (2006), una elevada autoeficacia académica (o percepción de que puede obtener un buen resultado académico por sus capacidades), puede provocar que el estudiante muestre un mayor interés en el trabajo académico, se proponga metas más ambiciosas, haga frente a las dificultades y acepte desafíos académicos orientados a mayor competencia. Por su parte, aquellos estudiantes que perciban en sí mismos una autoeficacia menor perseguirán un resultado académico menor y emplearán menos recursos en su proceso de aprendizaje (Usher y Pajares, 2006). Así, la autoeficacia juega un importante papel en el desarrollo del estudiante y en el uso de sus capacidades académicas (Zimmerman, 2000; Caballero, 2006). En esta línea, trabajos previos han comprobado que la autoeficacia tiene un efecto positivo en la orientación al aprendizaje (Kaplan y Maehr, 1999; Bong, 2001; Smith, Sinclair y Chapman, 2002; Greene, Miller, Crowson, Duke y Akey, 2004; Sullivan, Guerra y Hsieh, 2007; Fenollar, Román y Cuestas, 2008). Del mismo modo, se puede esperar que menores niveles de autoeficacia se traduzcan en una mayor orientación a evitar tareas, pues el alumno se sentirá en una peor situación para desarrollar dichas tareas académicas de forma eficaz (Joo, Bong y Choi, 2000; Sullivan, Guerra y Hsieh, 2007); si bien el estudio de Fenollar, Román y Cuestas (2008) no encontró diferencias significativas en este sentido.

Dicha relación no es tan evidente cuando se trata de la orientación a los resultados. Quienes tienen una alta autoeficacia académica se sienten seguros de su capacidad para afrontar las dificultades y son, además, más optimistas (Pajares, 1996). Fenollar, Román y Cuestas (2008) explican que ello implica que estos estudiantes no precisan demostrar una capacidad que tienen asumida. Es decir, no se puede hablar de relación entre autoeficacia y preocupación por mostrar competencia a los demás. En esta línea, autores como Pajares, Hartley y Valiante (2001) no encontraron relación significativa entre ambos conceptos. Sin embargo, Gao y Xiang (2007), en su estudio con 276 escolares, sí que evidenciaron dicha relación. Del mismo modo, Phillips y Gully (1997) comprobaron como la autoeficacia percibida por el estudiante se relaciona

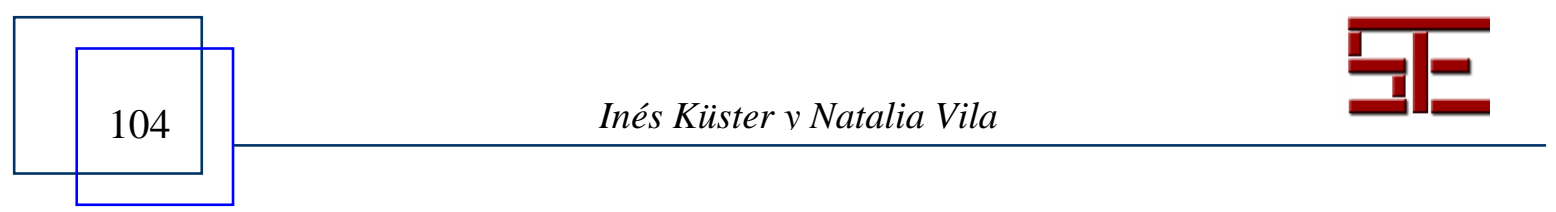




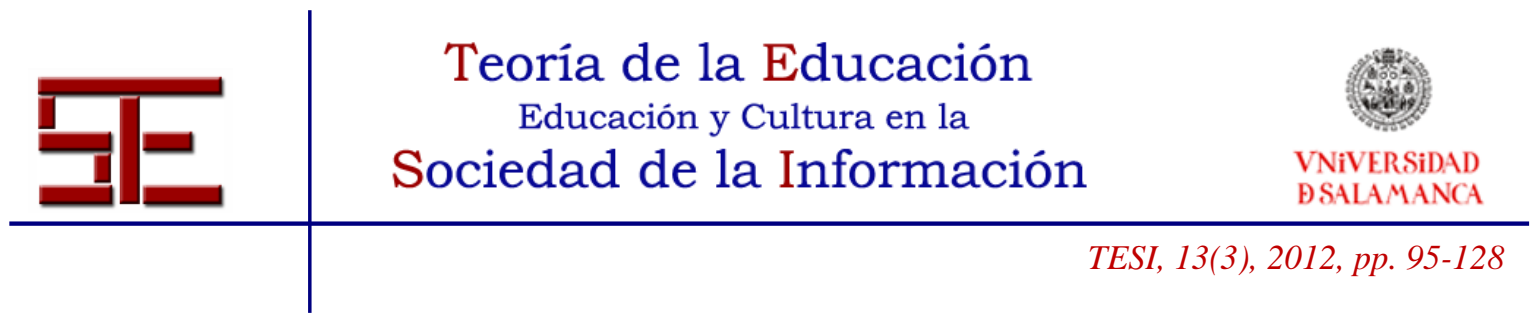

positivamente con la orientación al aprendizaje mientras que dicha relación es negativa con relación a la orientación al resultado. Por tanto, y pese que en el trabajo de Fenollar, Román y Cuestas (2008) no se establece una relación significativa entre orientación al resultado y autoeficacia, en el presente trabajo se defiende que dicha relación existe.

Lo expuesto en líneas previas, nos lleva a plantear las siguientes hipótesis:

Hipótesis 1 a-c: La autoeficacia académica percibida por el estudiante tiene (a) un efecto positivo en su orientación al aprendizaje, (b) un efecto negativo en su orientación al resultado y $(c)$ un efecto negativo en su orientación a evitar tareas.

Como se ha indicado anteriormente, la autoeficacia resulta beneficiosa para el rendimiento académico del estudiante. Así, diversos estudios han probado lo beneficiosa que es la autoeficacia en el ámbito docente (Pajares y Kranzler, 1995; Greene y Miller, 1996; Pajares y Valiente, 1997; Pajares, Hartley y Valiante, 2001; Greene, Miller, Crowson, Duke y Akey, 2004; Fenollar, Román y Cuestas, 2008). Los estudiantes que se sienten competentes, eficaces, son efectivos, activos participantes que producen resultados deseados (Ross y Broh, 2000).

En este sentido, y de acuerdo con Caballero (2006), un estudiante con bajos niveles de autoeficacia tendrá también un bajo rendimiento y, probablemente, evitará participar en las actividades que le sean asignadas. En cambio, un estudiante con alta autoeficacia se compromete más con la actividad encomendada y muestra una mayor persistencia, a pesar de las dificultades con las que se puede encontrar y, por lo tanto, mayor satisfacción académica. Es decir, la autoeficacia que el estudiante perciba de sí mismo influirá también en su rendimiento académico. De este modo, se establece la siguiente hipótesis

Hipótesis 2 a-b: La autoeficacia percibida por el estudiante tiene un efecto positivo (a) en su aprendizaje percibido y (b) en su nota esperada.

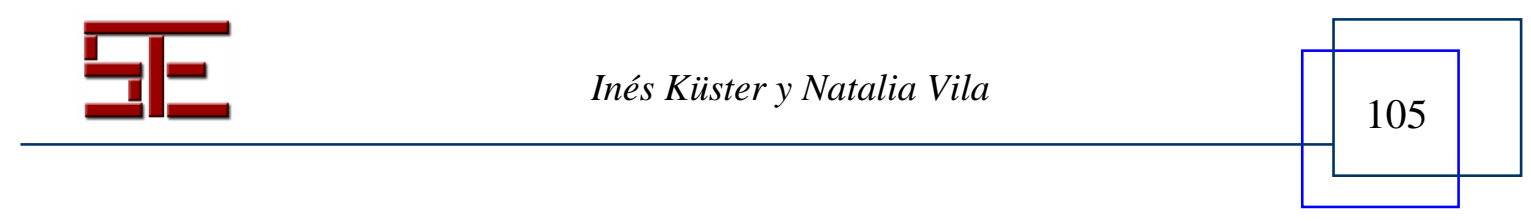




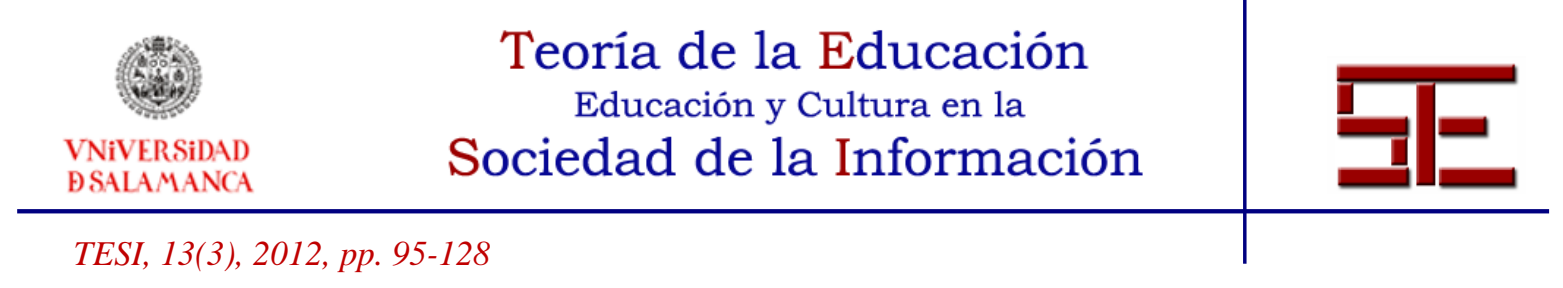

\subsection{Las orientaciones/motivaciones y sus efectos}

Con relación al segundo grupo de hipótesis (H8 a H10), justificamos a continuación el efecto directo de las orientaciones al aprendizaje, al rendimiento y a evitar tareas que lleve a cabo el estudiante sobre el rendimiento académico que finalmente espere obtener, en términos de aprendizaje percibido y nota esperada.

Así, aquellos estudiantes que poseen una orientación al aprendizaje "tienen un mayor deseo de mejorar su competencia y aumentar los conocimientos a partir de un esfuerzo de aprendizaje continuo y una mayor perseverancia en el estudio" (Murphy y Alexander, 2000, 28). Estos estudiantes no sólo están preocupados por sus resultados académicos respecto a los demás, sino que se interesan por proteger su imagen de competencia (Vermetten, Lodewijks y Vermunt, 2001). Así, se puede afirmar que un estudiante orientado al aprendizaje estudia los contenidos de la asignatura con la finalidad de comprenderlos, buscando las aplicaciones posteriores y relacionando entre sí los distintos conceptos que va adquiriendo (Kaplan y Midgley, 1997).

De acuerdo con Fenollar, Román y Cuestas (2008), a pesar de que algunos estudios no han obtenido un efecto significativo de la orientación al aprendizaje sobre el rendimiento académico, existe un considerable número de trabajos que sí que han encontrado un efecto positivo y significativo (Ames, 1992; Miller, Behrens, Greene y Newman, 1993; Greene y Miller, 1996; Dupeyrat y Mariné, 2005; Fenollar, Román y Cuestas, 2008). Por tanto, esperamos una relación positiva y significativa entre la orientación al aprendizaje que desarrolle el estudiante y el rendimiento académico que espere lograr; esto es:

Hipótesis 3 a-b: La orientación al aprendizaje del estudiante tiene un efecto positivo en (a) su aprendizaje percibido y (b) en la nota esperada por el estudiante.

Por otra parte, la orientación al resultado surge cuando el individuo se preocupa principalmente por obtener resultados positivos con el objeto de mostrar capacidad a los demás, independientemente de las actividades que lleve a cabo para conseguir dichas metas (Dweck, 1986). Esta necesidad de mostrar capacidad o competencia se manifiesta como un deseo de influir en el entorno, lo que le proporciona información al estudiante

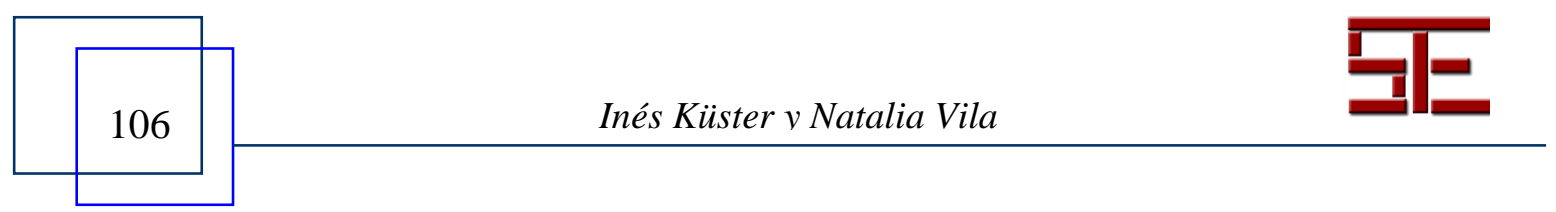




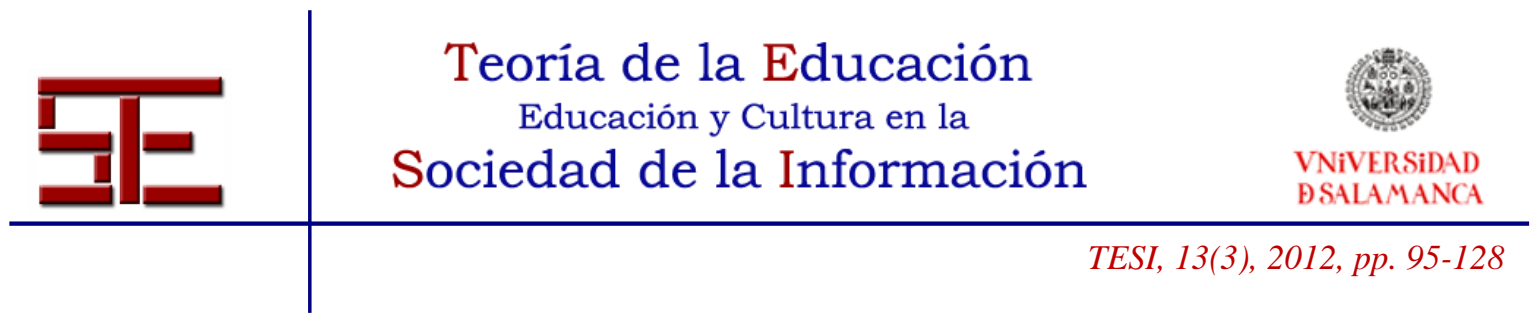

sobre su competencia, aspecto esencial para que éste se sienta bien (Elliot y Moller, 2003).

De acuerdo con Fenollar, Román y Cuestas (2008), en el ámbito docente no existe un patrón claro en relación al efecto de este tipo de orientación en el rendimiento del estudiante. Si bien diversos estudios no han encontrado un efecto significativo, otros sí han podido demostrar una relación significativa y positiva (p. e. Elliott, Shell, Henry y Maier, 2005). Como afirman los propios autores, una posible explicación podría encontrarse en la delimitación de qué se entiende por rendimiento del estudiante. Así es posible que los alumnos con una orientación al resultado obtengan una mejor nota, pero no necesariamente aprendan más frente a otros alumnos con una menor orientación al resultado (Fenollar, Román y Cuestas, 2008). Este argumento es también avalado por Elliot, McGregor y Gable (1999), quienes argumentan que los alumnos con una orientación al resultado tienden a adoptar como estrategias de estudio la memorización y la repetición de conceptos clave, que en determinadas circunstancias pueden dar lugar a resultados académicos positivos (en términos de notas), pero difícilmente a un mayor aprendizaje. No obstante, en términos generales cabe enunciar un efecto positivo y directo de la orientación al resultado sobre el rendimiento esperado por el estudiante, medido éste en términos de aprendizaje percibido y nota esperada. Por lo tanto planteamos que:

Hipótesis $4 a-b$ : La orientación al resultado del estudiante tiene un efecto positivo en (a) su aprendizaje percibido y (b) en la nota esperada por el estudiante.

Finalmente, y como se ha indicado anteriormente, los estudiantes que muestran una orientación a evitar tareas intentan realizar la tarea académica con el menor esfuerzo posible para evitar consecuencias negativas, como el fracaso académico. Los trabajos que han considerado esta variable han puesto de manifiesto sus efectos negativos (Fenollar, Román y Cuestas, 2008). Así, por ejemplo, Dupeyrat y Mariné (2005) encontraron que la orientación a evitar tareas está significativamente relacionada con el uso de estrategias de estudio superficiales, tales como la memorización. De forma similar, la orientación a evitar tareas se ha demostrado que está asociada con un rendimiento académico bajo (Nurmi, Onatsu y Haavisto, 1995; Fenollar, Román y Cuestas, 2008). A la vista de lo expuesto, se plantea la siguiente hipótesis:

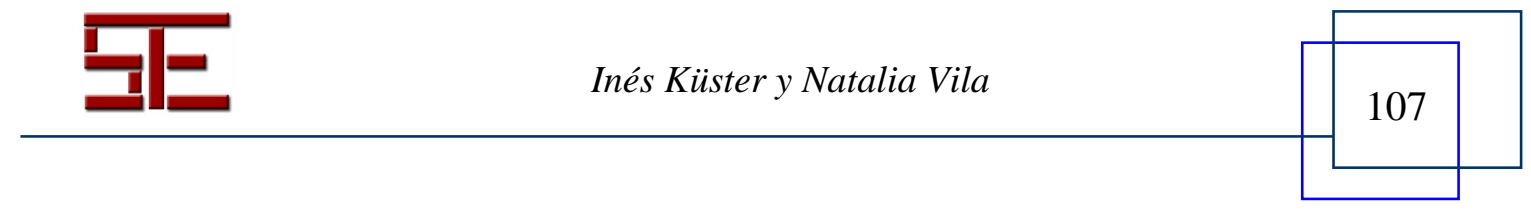




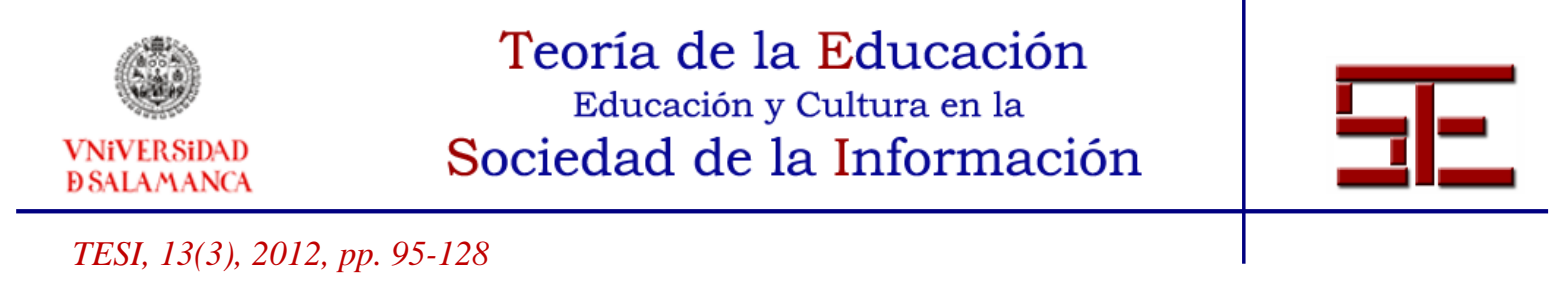

Hipótesis 5 a-b: La orientación a evitar tareas del estudiante tiene un efecto negativo (a) en su aprendizaje percibido y (b) en la nota esperada por el estudiante.

\subsection{El aprendizaje percibido y sus efectos}

El tercer grupo de hipótesis (H6) plantea un efecto del aprendizaje percibido sobre la nota esperada. Así, se puede considerar que la docencia ha sido efectiva si consigue mejorar los resultados del estudiante, después de un período de instrucción; y ello de una forma coherente con los objetivos docentes planteados (Marsh, 1987). En este sentido, Marsh (1987) señala que uno de los criterios más aceptados para evaluar la efectividad es el aprendizaje del estudiante. Asimismo, la efectividad en la docencia hace referencia a la capacidad de modificar los conocimientos y habilidades del estudiante en un período de tiempo dado (Fenollar, Román y Cuestas, 2008). En esta línea, Olivares (2001) y Fenollar, Román y Cuestas (2008) comprobaron que el aprendizaje percibido está positivamente relacionado con la nota esperada por el estudiante. En consecuencia se plantea la siguiente hipótesis:

Hipótesis 6: El aprendizaje percibido por el estudiante tiene un efecto positivo en la nota esperada.

Finalmente, se intenta justificar la relación entre el rendimiento académico y la satisfacción global del estudiante (H12 a y b). En este sentido, Petruzzellis, D’Uggento y Romanazzi (2006) llevan a cabo un estudio para comprobar las razones que conllevan la satisfacción del estudiante hacia los estudios. Los autores comprobaron como los dos factores más relevantes y significativos en la satisfacción del estudiante eran la capacidad de poder cubrir sus necesidades de manera genérica y la capacidad de alcanzar un buen nivel de educación. Por tanto, cabe plantear que aquellos estudiantes donde el aprendizaje percibido y la nota esperada sea mayor muestren niveles de satisfacción más elevados.

De manera más específica, Caballero, Abello y Palacio (2007) pudieron comprobar en una muestra compuesta por 213 estudiantes universitarios la existencia de una relación positiva entre rendimiento académico alcanzado por el estudiante en términos de puntuaciones promedias y su satisfacción en los estudios. Igualmente, Fredericksen, Pickett, Shea, Pelz y Swan (1999) en el contexto de la docencia online obtuvieron que el

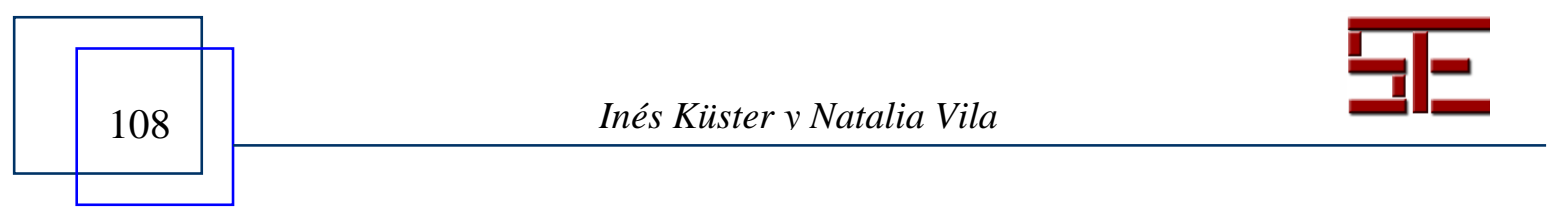




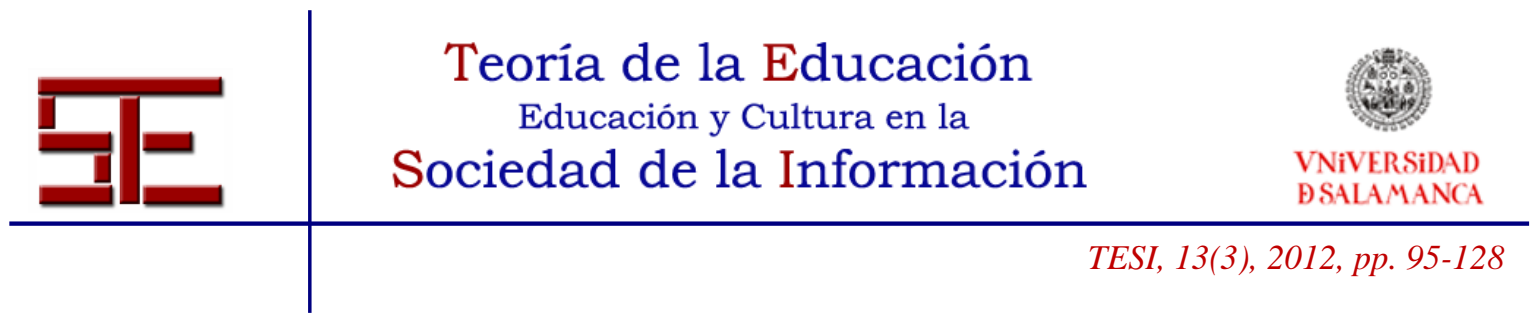

aprendizaje percibido se relacionaba de manera positiva con la satisfacción del estudiante hacia el curso.

Por tanto, a la vista de lo expuesto, cabe plantear la siguiente hipótesis:

Hipótesis 7: (a) El aprendizaje percibido y (b) la nota esperada por el estudiante tienen un efecto positivo en la satisfacción global del estudiante.

\section{METODOLOGÍA}

El propósito de este apartado es exponer la metodología de investigación que se ha seguido a fin de contrastar las hipótesis propuestas. Para ello, se discuten los temas referentes al objeto de estudio como son la selección de la población y determinación de la muestra, recogida de la información, técnicas de análisis de datos, medición de las variables y validación de las escalas propuestas.

\subsection{Población objeto de análisis}

El objetivo de este trabajo se centra en analizar el papel que juega el estudiante universitario en su propio rendimiento y satisfacción. En este sentido, y de acuerdo con Gullason (2009), durante los últimos años, ha habido un gran interés académico en la mejora de la eficacia de la enseñanza en la disciplina de la economía. Dicho interés se inició en la primera mitad de los años noventa consecuencia de un leve descenso en los estudios en esta materia (Gullason, 2009). Como el propio autor señala, este interés no ha decrecido pese a la recuperación posterior en el número de especialidades y cursos ofertados en economía; interés que se ha centrado en analizar aquellas estrategias educativas que mejoran el rendimiento del estudiante.

En este ámbito, la presente investigación se centra en una Facultad de Economía. Dicha institución cuenta con unos 9.000 estudiantes que actualmente pueden cursar 6 titulaciones de grado y 13 titulaciones de postgrado oficial.

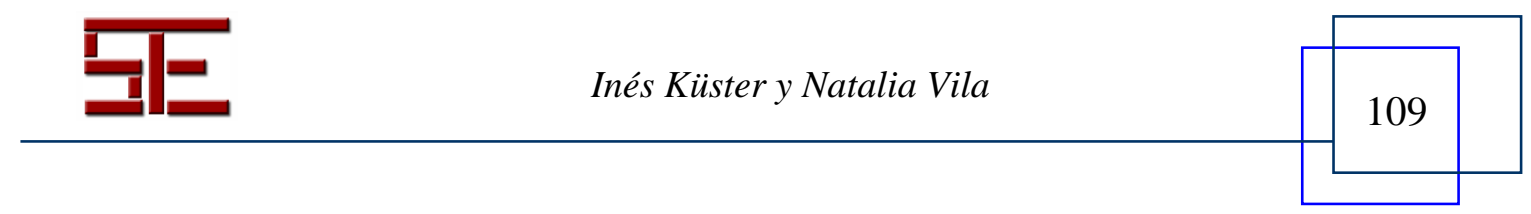




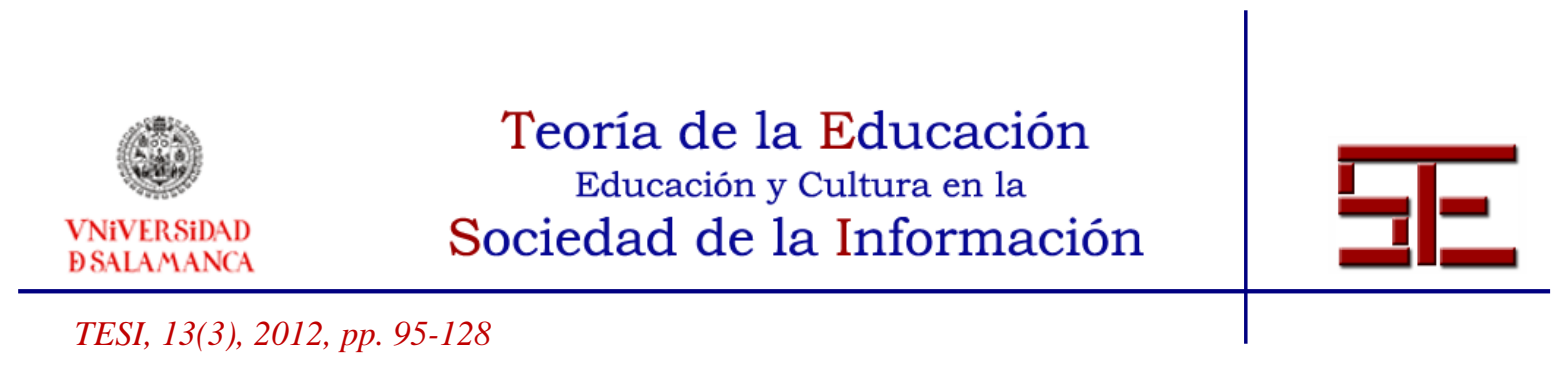

\subsection{Determinación de la muestra y recogida de información}

A fin de contrastar las hipótesis planteadas, se llevó a cabo un estudio empírico de naturaleza cualitativa (en la fase exploratoria de la investigación) y cuantitativa (en su fase analítica), además de transaccional, porque de cada sujeto de estudio se recabó información una sola vez, correlacional/causal porque se describen las relaciones existentes entre dos o más variables en un momento determinado y explicativo porque trata de responder a las preguntas establecidas al principio del presente trabajo.

Se ha considerado como unidad de análisis a los estudiantes de una Facultad de Economía, a los que se les preguntaba sobre su grado de orientación hacia la carrera, así como sobre aspectos relacionados con su autoeficacia, rendimiento académico esperado (aprendizaje percibido y nota esperada) y satisfacción hacia una determinada asignatura.

Se ha seguido un procedimiento de muestreo no probabilístico por conveniencia. A pesar de las limitaciones propias de las muestras no aleatorias (Kinnear y Taylor, 1991; Aaker, Kumar y Day, 2001; Zikmund, 2003; Malhotra y Birks, 2007), su uso resulta útil si el juicio de los expertos es válido (Kinnear y Taylor, 1991; Malhotra y Birks, 2007). Este procedimiento dio lugar a un total de 932 cuestionarios.

En la Tabla 1 se puede observar que hubo una mayoría de cuestionarios cumplimentados por mujeres $(64,3 \%)$ frente al $35,7 \%$ de hombres. El $57 \%$ hacen referencia a opiniones de estudiantes sobre materias impartidas en licenciatura (primer y segundo ciclo), seguido de un $33 \%$ de opiniones de asignaturas impartidas en diplomaturas (primer ciclo) y de un $9,4 \%$ de opiniones relativas a materias impartidas en másteres oficiales (postgrado). El 71,7\% de los cuestionarios recogían opiniones de estudiantes que no trabajan, frente al 28,3\% de estudiantes que compaginan sus estudios con una actividad laboral. Esta situación podría explicar que con una media de edad de 22 años, haya estudiantes desde 17 años hasta 54 años. El perfil de la muestra obtenida de estudiantes no difiere del perfil de la población objeto de estudio.

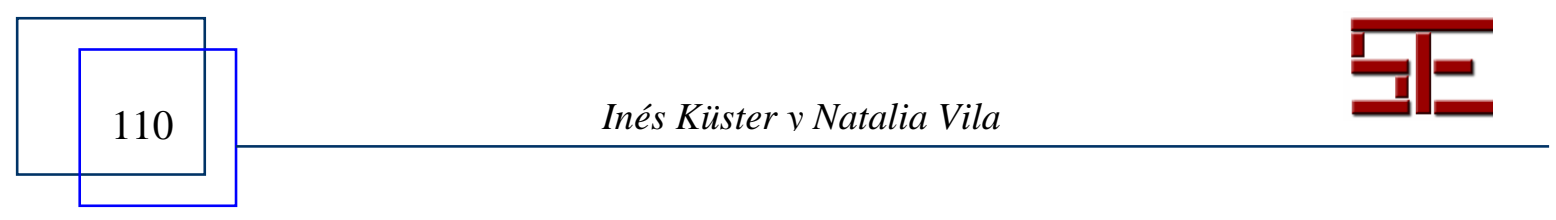




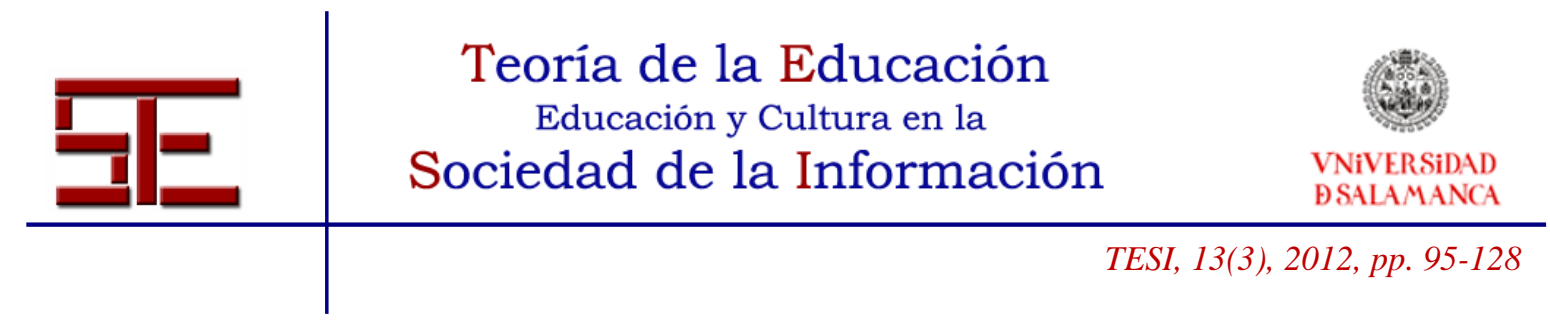

Tabla 1. Perfil de la muestra de estudiantes

\begin{tabular}{llcc}
\hline Variable & Categoría & Frecuencia & Porcentaje \\
\hline \multirow{2}{*}{ Sexo } & Hombre & 333 & 35,7 \\
& Mujer & 599 & 64,3 \\
\hline \multirow{3}{*}{ Estudios } & Diplomatura & 313 & 33,6 \\
& Licenciatura & 531 & 57,0 \\
& Master oficial & 88 & 9,4 \\
\hline \multirow{2}{*}{ Trabajo } & Sí & 264 & 28,3 \\
& No & 668 & 71,7 \\
\hline
\end{tabular}

\subsection{Medición de variables}

Se muestran a continuación los diversos instrumentos empleados para la medición de las variables que componen el modelo planteado. Como se aprecia en la Tabla 2, todas las escalas utilizadas son escalas multiítem (salvo la de satisfacción global y la nota esperada), de tipo Likert de grado cinco.

Tabla 2. Escalas empleadas en la investigación: los estudiantes

\begin{tabular}{|c|c|c|c|}
\hline Concepto/Fuente & Factor & Indicador & Enunciado \\
\hline \multirow{5}{*}{$\begin{array}{c}\text { Orientación al } \\
\text { aprendizaje } \\
\text { OA } \\
\text { Midgley, Kaplan, } \\
\text { Middleton, Maehr, } \\
\text { Urdan, Anderman, } \\
\text { Anderman y Roeser } \\
\text { (1998) }\end{array}$} & \multirow{5}{*}{$\mathrm{OA}$} & OA1 & $\begin{array}{l}\text { Me gusta realizar prácticas con las que aprendo, } \\
\text { aunque me equivoque haciéndolas }\end{array}$ \\
\hline & & OA2 & $\begin{array}{l}\text { Una de las razones por las que estudio es porque me } \\
\text { gusta aprender cosas nuevas }\end{array}$ \\
\hline & & OA3 & Me gusta estudiar, sobre todo cuando me hace pensar \\
\hline & & OA4 & $\begin{array}{l}\text { Una de las razones por las que estudio es para } \\
\text { dominar los contenidos de la asignatura }\end{array}$ \\
\hline & & OA5 & Para mí, el estudio resulta interesante \\
\hline \multirow{5}{*}{$\begin{array}{c}\text { Orientación al } \\
\text { aprendizaje } \\
\text { ORDO } \\
\text { Midgley, Kaplan, } \\
\text { Middleton, Maehr, } \\
\text { Urdan, Anderman, } \\
\text { Anderman y Roeser } \\
\text { (1998) }\end{array}$} & \multirow{5}{*}{ ORDO } & ORDO1 & $\begin{array}{l}\text { Quiero obtener mejores resultados que mis } \\
\text { compañeros }\end{array}$ \\
\hline & & ORDO2 & $\begin{array}{l}\text { Me siento muy bien cuando lo hago mejor que la } \\
\text { mayoría de mis compañeros de clase }\end{array}$ \\
\hline & & ORDO3 & $\begin{array}{l}\text { Me sentiría realmente bien si fuera el único que } \\
\text { pudiera contestar a las preguntas del profesor en la } \\
\text { clase }\end{array}$ \\
\hline & & ORDO4 & $\begin{array}{l}\text { Me gusta demostrar a los profesores que sé más que } \\
\text { el resto de alumnos }\end{array}$ \\
\hline & & ORDO5 & $\begin{array}{l}\text { Para mí es importante hacer las cosas en clase mejor } \\
\text { que mis compañeros }\end{array}$ \\
\hline $\begin{array}{l}\text { Orientación evitar } \\
\text { tareas }\end{array}$ & OET & OET1 & $\begin{array}{l}\text { Deseo que en las clases no nos manden muchos } \\
\text { trabajos/prácticas }\end{array}$ \\
\hline
\end{tabular}

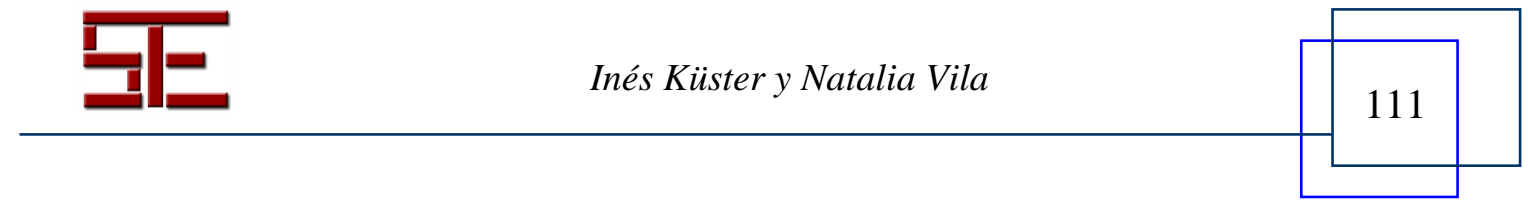




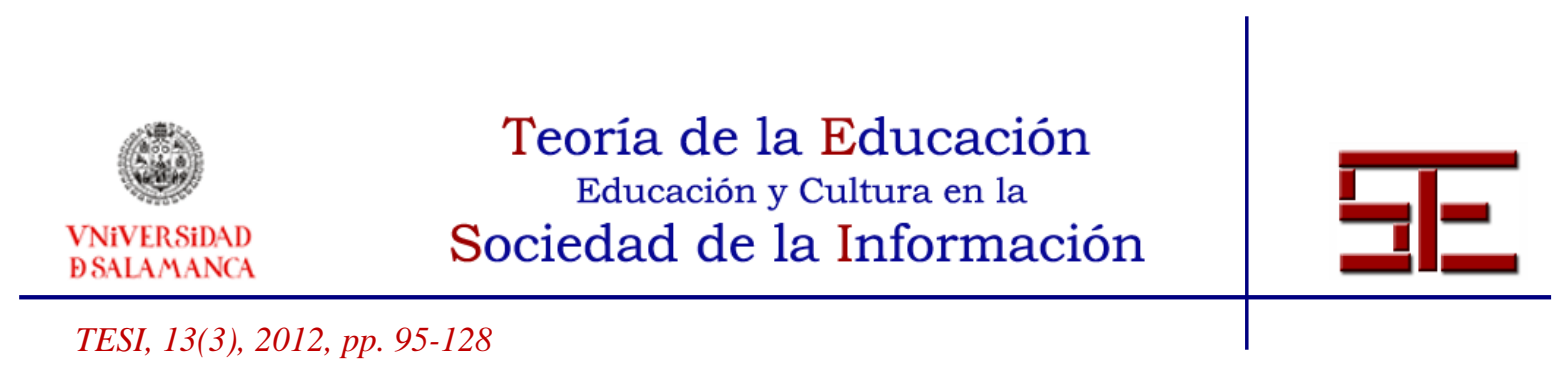

\begin{tabular}{|c|c|c|c|}
\hline \multirow[t]{2}{*}{$\begin{array}{c}\text { OET } \\
\text { Skaalvik (1997) }\end{array}$} & & OET2 & $\begin{array}{l}\text { Me gustan las asignaturas en las que no hay que hacer } \\
\text { muchas prácticas/trabajos }\end{array}$ \\
\hline & & OET3 & $\begin{array}{l}\text { Una asignatura me gusta más cuanto menos tengo } \\
\text { que hacer para aprobar }\end{array}$ \\
\hline \multirow{8}{*}{$\begin{array}{l}\text { Autotoeficacia } \\
\text { AUTO } \\
\text { Greene y Miller } \\
\text { (1996) }\end{array}$} & \multirow{8}{*}{ AUTO } & AUTO1 & $\begin{array}{l}\text { Estoy seguro de que puedo obtener buenos resultados } \\
\text { con esta asignatura si me lo propongo }\end{array}$ \\
\hline & & AUTO2 & $\begin{array}{l}\text { Si no entiendo algún aspecto de esta asignatura } \\
\text { persisto hasta que lo comprendo }\end{array}$ \\
\hline & & AUTO3 & $\begin{array}{l}\text { El hecho de saber que hay gente que ha suspendido la } \\
\text { asignatura me hace ser más determinado para sacar } \\
\text { buenos resultados en el examen }\end{array}$ \\
\hline & & AUTO4 & $\begin{array}{l}\text { Confío en que estaré suficientemente preparado para } \\
\text { afrontar con éxito este examen }\end{array}$ \\
\hline & & AUTO5 & $\begin{array}{l}\text { Tiendo a posponer enfrentarme a los problemas } \\
\text { relacionados con esta asignatura cuando aparecen }\end{array}$ \\
\hline & & AUTO6 & $\begin{array}{l}\text { No importa cuánto me esfuerce, no progreso en los } \\
\text { temas relacionados con esta asignatura }\end{array}$ \\
\hline & & AUTO7 & $\begin{array}{l}\text { Estoy convencido de que finalmente comprenderé los } \\
\text { aspectos de esta asignatura que todavía no domino }\end{array}$ \\
\hline & & AUTO8 & Espero dar lo mejor de mí mismo en el examen \\
\hline \multirow{8}{*}{$\begin{array}{c}\text { Aprendizaje } \\
\text { percibido } \\
\text { Marsh (1987) y } \\
\text { Marsh y Hocevar } \\
\text { (1991) }\end{array}$} & \multirow{8}{*}{ AP } & AP1 & $\begin{array}{l}\text { Creo que lo que aprendo en esta asignatura es } \\
\text { importante }\end{array}$ \\
\hline & & AP2 & Creo que esta asignatura es muy útil \\
\hline & & AP3 & Encuentro esta asignatura muy interesante \\
\hline & & AP4 & Encuentro esta asignatura estimulante y desafiante \\
\hline & & AP5 & $\begin{array}{l}\text { He aprendido cosas en esta asignatura que considero } \\
\text { valiosas }\end{array}$ \\
\hline & & AP6 & $\begin{array}{l}\text { Mi interés por los contenidos de esta asignatura ha } \\
\text { aumentado como consecuencia de haberla cursado }\end{array}$ \\
\hline & & AP7 & $\begin{array}{l}\text { He aprendido y comprendido los contenidos de esta } \\
\text { asignatura }\end{array}$ \\
\hline & & AP8 & $\begin{array}{l}\text { Desde el inicio del curso a la fecha, ¿cómo ha } \\
\text { evolucionado tu interés por esta asignatura? (piensa } \\
\text { en la labor del profesor, el contenido, etc.) }\end{array}$ \\
\hline $\begin{array}{l}\text { Nota esperada } \\
\text { Fenollar, Román y } \\
\text { Cuestas (2008) } \\
\end{array}$ & $\mathrm{NE}$ & NE & $\begin{array}{l}\text { ¿Qué nota esperas sacar en esta asignatura en los } \\
\text { exámenes que comenzarán en unos meses? }\end{array}$ \\
\hline Satisfacción global & SG & SG & $\begin{array}{l}\text { ¿Podrías indicar tu grado de satisfacción global con } \\
\text { esta asignatura? }\end{array}$ \\
\hline
\end{tabular}

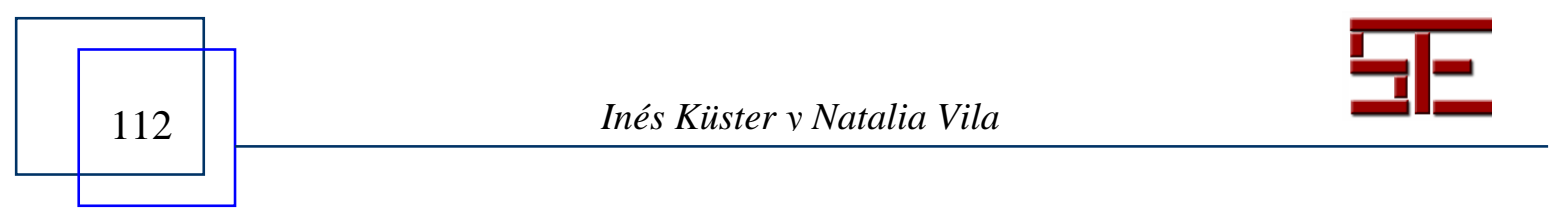




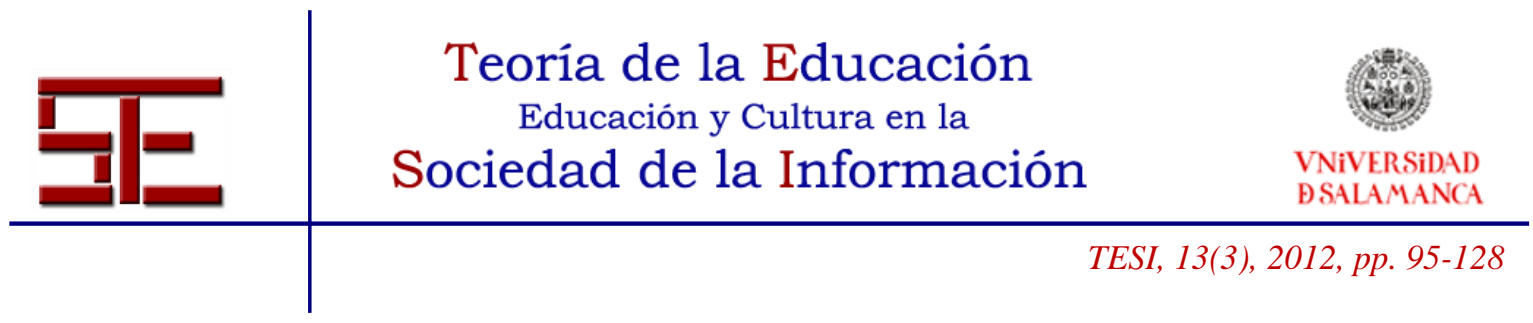

\subsection{Técnicas de análisis de datos}

La naturaleza de las diferentes hipótesis ha condicionado el uso de las diferentes técnicas de análisis estadístico. Es necesario aclarar que diversos fueron los pasos seguidos. En primer lugar, se validó y testó el modelo planteado relativo al rendimiento de los estudiantes. Para ello se empleó el modelo de ecuaciones estructurales o modelo multivariante de segunda generación, el PLS (Partial Least Squares), que no presupone una distribución normal de los datos y que permite evaluar simultáneamente el modelo de medida y el modelo teórico (Lawson-Body y O'Keefe, 2006).

Así, y siguiendo una metodología similar a la de otros autores (p. e. Sánchez-Franco y Roldán, 2005), el modelo de PLS fue analizado e interpretado en dos fases: (1) evaluación de la fiabilidad y validez del modelo de medida, y (2) evaluación del modelo estructural. La estimación del modelo se realizó con SmartPLS 2.0 (Ringle, Wende y Alexander, 2005). Asimismo, la estimación de la significatividad de los parámetros se realizó mediante el procedimiento de boostraping con 400 sub-muestras, con un tamaño muestral igual al de la muestra original de 932 casos. De esta forma, se pudo validar el instrumento de medida, así como testar las hipótesis planteadas.

\section{ANÁLISIS Y DISCUSIÓN DE RESULTADOS}

En primer lugar se llevó a cabo la evaluación de las propiedades psicométricas de las escalas utilizadas. Así, se comenzó analizando las cargas factoriales de los distintos ítems y su fiabilidad individual. La fiabilidad individual de cada ítem se considera adecuada cuando un ítem posee una carta factorial superior a 0,7 , lo que implica una varianza entre una variable y sus indicadores superior a la varianza del error (Carmines y Zeller, 1979). En nuestro caso, fueron suprimidos 3 ítems de la variable de autoeficacia (A3, A5 y A6); y ello, por obtener valores inferiores a 0,7 (0,19, 0,09 y 0,46 , respectivamente).

Tabla 3. Fiabilidad y validez convergente del modelo de medida

\begin{tabular}{|c|c|c|c|c|c|c|c|}
\hline Concepto & Factor & Indicador & Carga & $\begin{array}{c}\text { Valor t } \\
\text { (bootstrapping) }\end{array}$ & $\begin{array}{c}\alpha \text { de } \\
\text { Cronbach }\end{array}$ & IFC & AVE \\
\hline \multirow{5}{*}{$\begin{array}{l}\text { Orientación } \\
\text { al } \\
\text { aprendizaje }\end{array}$} & \multirow{5}{*}{$\mathrm{OA}$} & OA1 & $0,58 * *$ & 15,99 & \multirow{5}{*}{0,74} & \multirow{5}{*}{0,82} & \multirow{5}{*}{0,49} \\
\hline & & OA2 & $0,80 * *$ & 50,58 & & & \\
\hline & & OA3 & $0,74 * *$ & 26,79 & & & \\
\hline & & OA4 & $0,56^{* *}$ & 14,70 & & & \\
\hline & & OA5 & $0,79 * *$ & 46,37 & & & \\
\hline
\end{tabular}

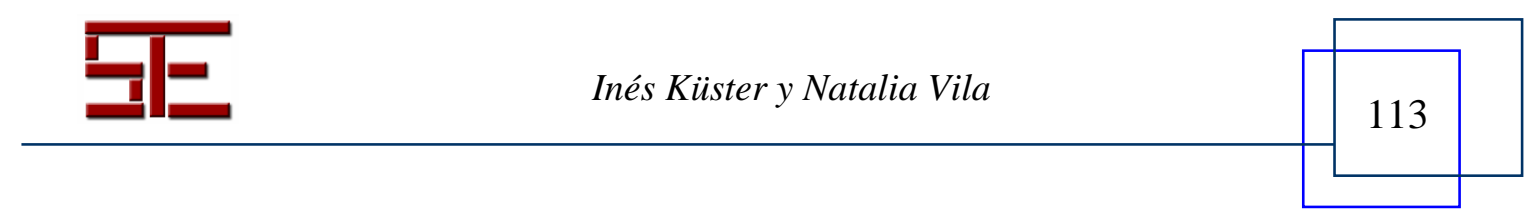




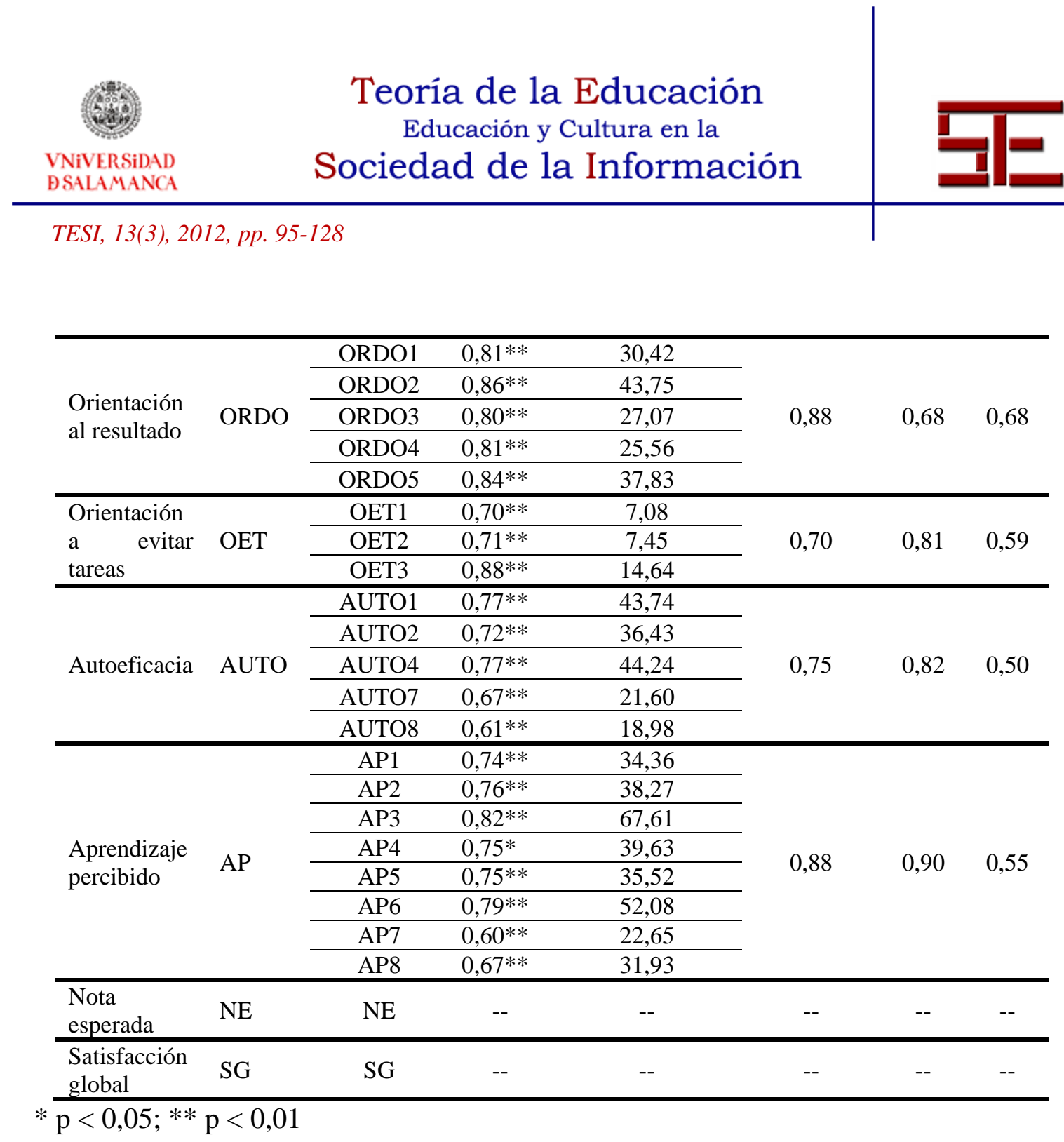

Ahora, si bien el $\alpha$ de Cronbach (Cronbach, 1951) supera la recomendación de 0,7 (Churchill, 1979), dicho coeficiente asume que los ítems están medidos sin error, lo cual no resulta plausible, por lo que tiende a subestimar la fiabilidad (Bollen, 1989). Por ello, fue también necesario calcular el índice de fiabilidad compuesta, cuyos valores también están próximos o superan el valor crítico recomendado de 0,7 (Fornell y Larcker, 1981). Adicionalmente, también se ha estimado la varianza promedio extraída (AVE), que es un indicador de la varianza capturada por un factor respecto a la varianza debida al error de medida (Fornell y Larcker, 1981). Los valores correspondientes están próximos o superan el valor 0,5. Así pues, junto con el análisis de cargas factoriales y el $\alpha$ de Cronbach, calculamos el índice de fiabilidad compuesta y el índice de la varianza extraída; todo ello a fin de evaluar la fiabilidad y validez convergente del modelo. Los

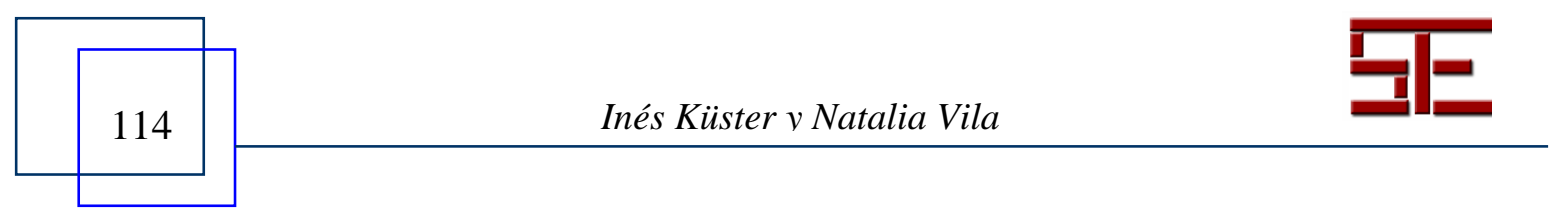




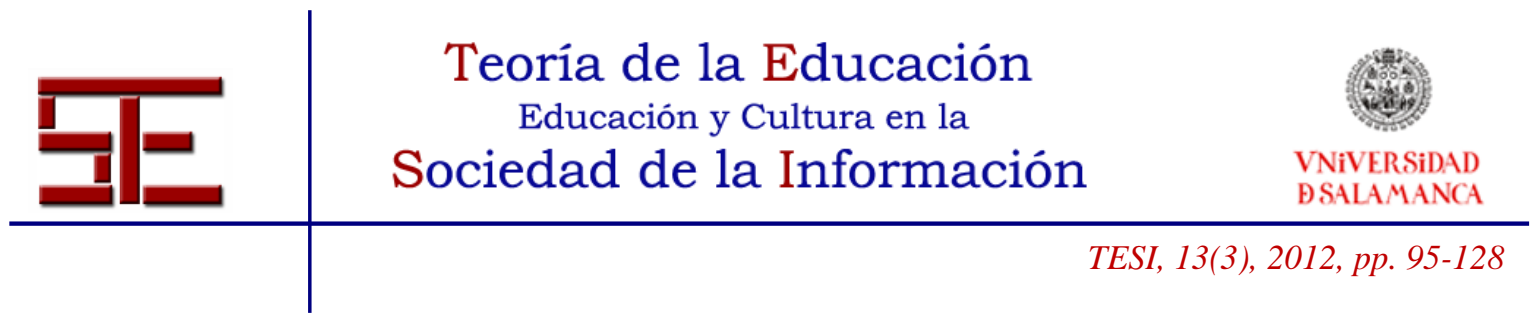

resultados comentados y mostrados en la Tabla 3 no evidencian problemas ni de fiabilidad ni de validez convergente para el modelo propuesto.

Por último, la validez discriminante se evalúa mediante la comparación entre los índices de la varianza extraída de cada variable latente y la varianza compartida entre ambas variables latentes, aproximada por el cuadrado de la correlación entre ambas (Barclay, Higgins y Thompson, 1995). Como puede observarse en la Tabla 4, la varianza extraída entre cada par de variables latentes siempre es superior al cuadrado de la correlación entre ambas; esto es, cada valor de la diagonal siempre es superior a todos los elementos de su fila y columna.

\begin{tabular}{|c|c|c|c|c|c|c|c|}
\hline & OA & ORDO & OFT & A UTTO & D & NF & \\
\hline OA & 0,49 & & & & & & \\
\hline ORDO & 0,28 & 0,68 & & & & & \\
\hline OET & 0,13 & 0,18 & 0,59 & & & & \\
\hline AUTO & 0,12 & 0,13 & 0,06 & 0,50 & & & \\
\hline $\mathbf{A P}$ & 0,02 & 0,01 & 0,01 & 0,13 & 0,55 & & \\
\hline NE & 0,01 & 0,02 & 0,02 & 0,00 & 0,00 & 1,00 & \\
\hline SG & 0,44 & 0,13 & 0,15 & 0,04 & 0,02 & 0,00 & 1,00 \\
\hline
\end{tabular}

Nota: Debajo de la diagonal, correlación estimada entre los factores al cuadrado.

En la diagonal, índice de la varianza extraída.

Analizadas la fiabibilidad, la validez convergente y la validez discriminante, procedimos a estimar el modelo estructural que nos permitía contrastar las hipótesis planteadas H1 a H7 (Figura 2). Se siguió el mismo procedimiento que en la valoración de la significatividad de los parámetros; es decir, mediante el procedimiento de bootstrapping de 400 submuestas del tamaño de la muestra original, 932 casos.

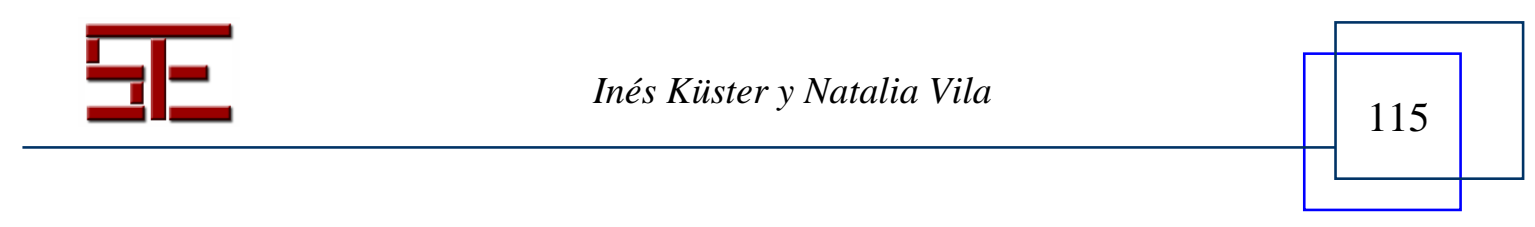




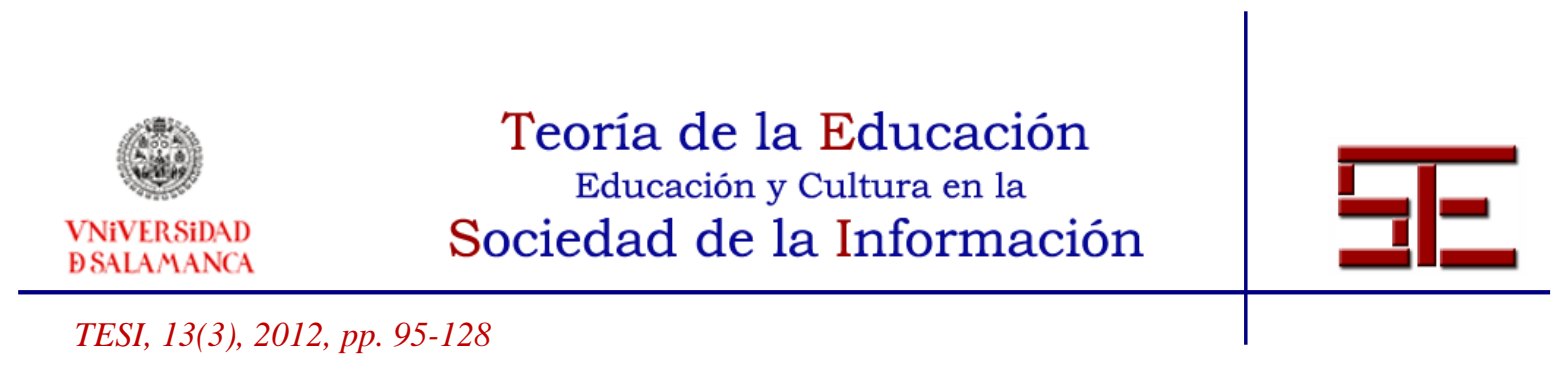

Figura 2. Estimación del modelo estructural de los estudiantes

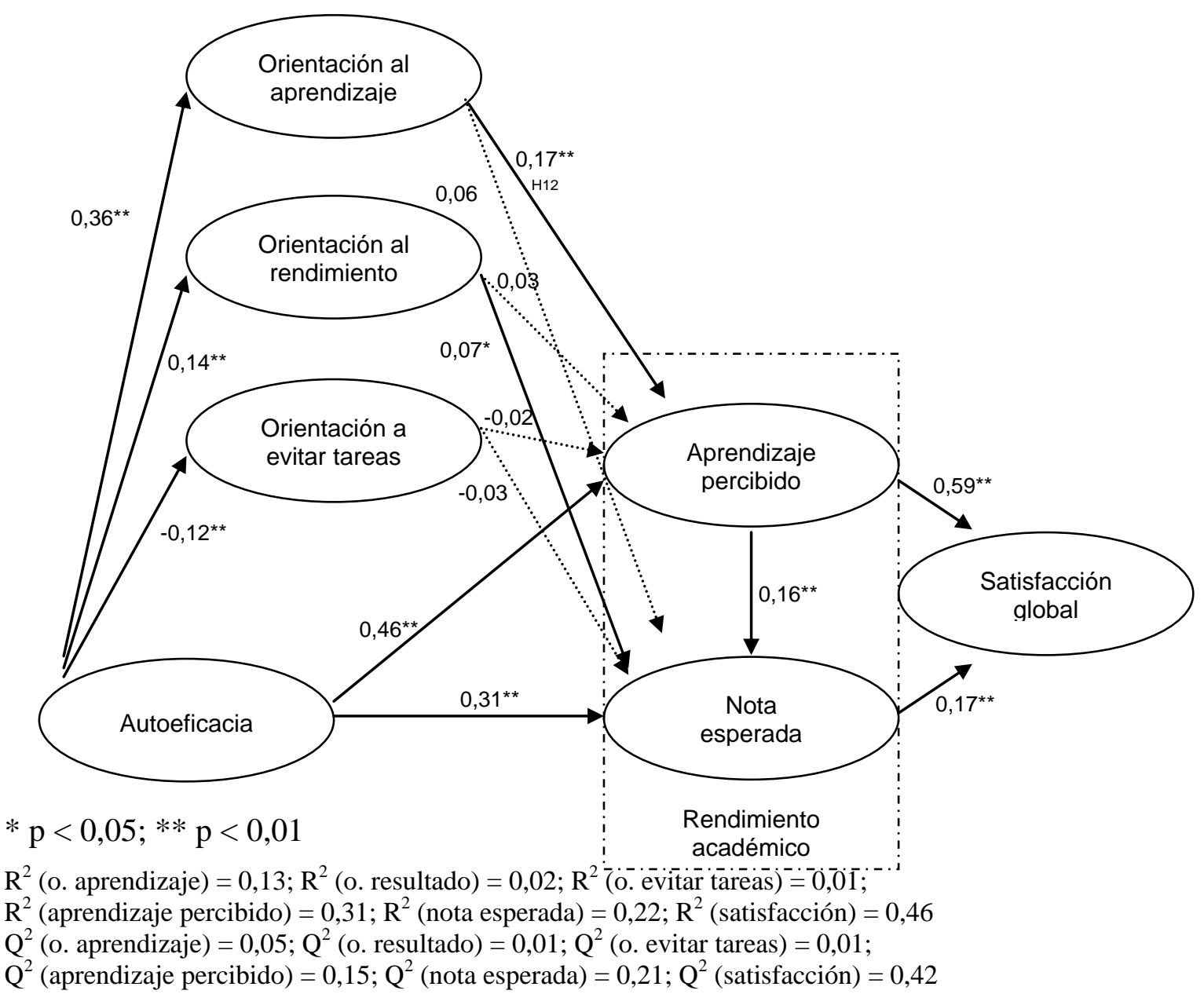

Tal y como se observa en la Figura 2, a excepción de 4 casos (H3b, H4a, H5 a y b), los coeficientes de regresión estandarizados del resto de hipótesis resultan significativos y permiten la aceptación de dichas hipótesis. Ahora bien, los resultados muestran un signo contrario al planteado en H1c (relación entre autoeficacia y orientación al resultado).

Junto a ello, la Figura 2 nos muestra las varianzas de las variables latentes dependientes explicadas por los constructos que se predicen mediante $\mathrm{R}^{2}$. Excepto en dos casos

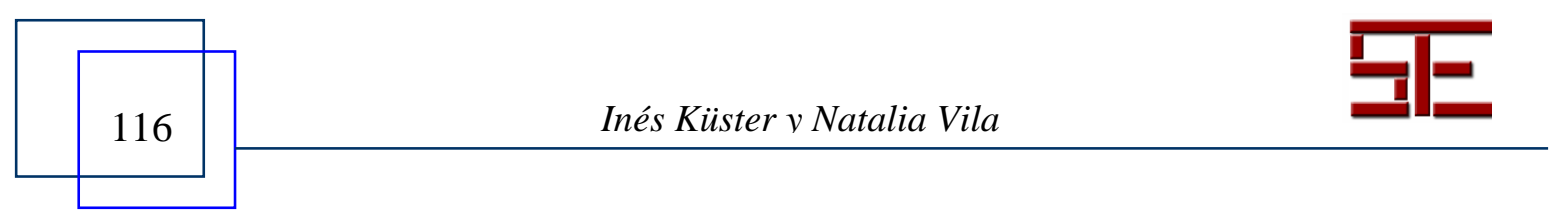




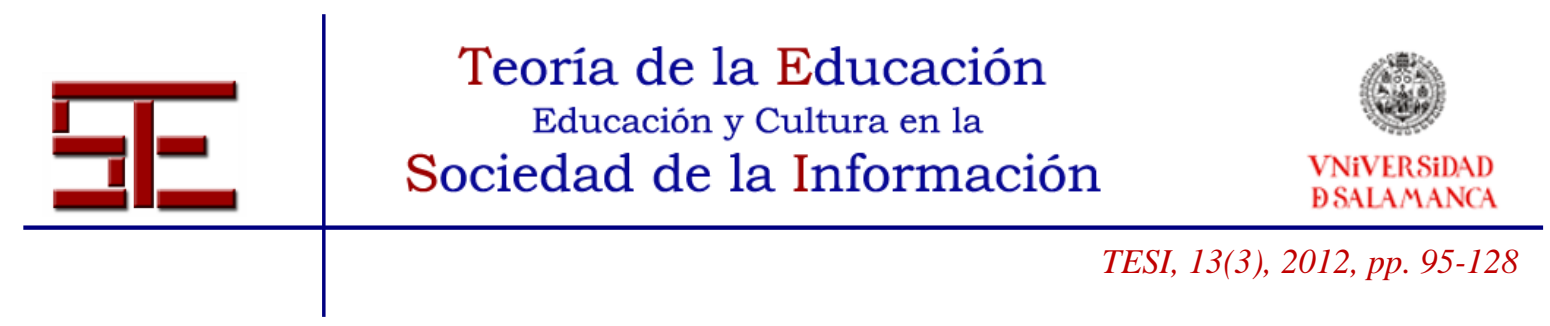

(orientación al resultado y orientación a evitar tareas), se supera el valor 0,1 . Ahora bien, fijar un valor mínimo arbitrario para el valor de la $\mathrm{R}^{2}$ es un planteamiento cada vez menos aceptado y se recomienda siempre efectuar pruebas de potencia sobre el estadístico. En el caso que nos ocupa, deberíamos comprobar cuál es el valor de la $\mathrm{R}^{2}$ que permite tener una certeza del $80 \%$ de que el estadístico $\mathrm{F}$ asociado a la regresión rechazará la hipótesis nula de que todos los parámetros son nulos cuando esta hipótesis sea falsa. Para una muestra de 932 casos y una variable independiente, se exigen valores $\mathrm{R}^{2}$ de al menos 0,1 para alcanzar una potencia del $80 \%$ (Hair, Black, Babin, Anderson y Tatham (2006:195). En nuestro caso, todos los valores sobrepasan dicho valor de 0,1.

Con relación a la relevancia predictiva, aplicamos un procedimiento de blindfolding, es decir, se omiten parte de los datos al estimar una variable latente dependiente a partir de otras variables latentes independientes, y luego se intenta estimar esos datos utilizando los parámetros estimados con anterioridad. Este proceso se repite hasta que cada dato ha sido omitido y estimado. El objetivo es determinar si la estimación de los valores perdidos que tiene en cuenta la información del modelo es mejor que la estimación que obvia esta estimación (sustitución por la media). En este sentido, el estadístico $Q^{2}$ se construye de tal forma que será positivo cuando el error cometido con la información del modelo es menor; esto es, cuando hay relevancia predictiva. En nuestro caso, y como puede observarse en la Figura 2, todos los valores son positivos.

Los resultados obtenidos revelan el papel decisivo que juega la percepción de autoeficacia que posee el estudiante sobre sí mismo en la motivación del estudiante (H1), así como en el rendimiento esperado por éste $(\mathrm{H} 2)$.

En cuanto a las orientaciones/motivaciones del estudiante, los resultados ponen de manifiesto: (1) Un efecto positivo y significativo de la orientación al aprendizaje sobre el aprendizaje percibido (H3a); y un efecto no significativo sobre la nota esperada (H3b). (2) Un efecto no significativo de la orientación al resultado sobre el aprendizaje percibido (H4a); y un efecto positivo y significativo sobre la nota esperada (H4b). Y (3) efectos no significativos de la orientación a evitar tareas sobre el aprendizaje percibido (H5a) y la nota esperada (H5b).

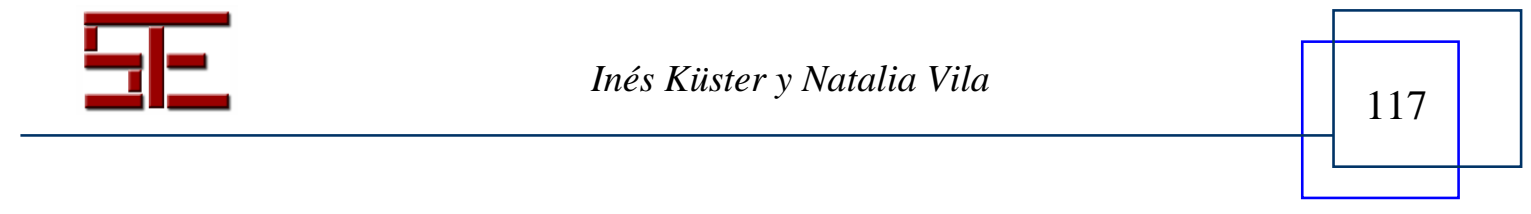




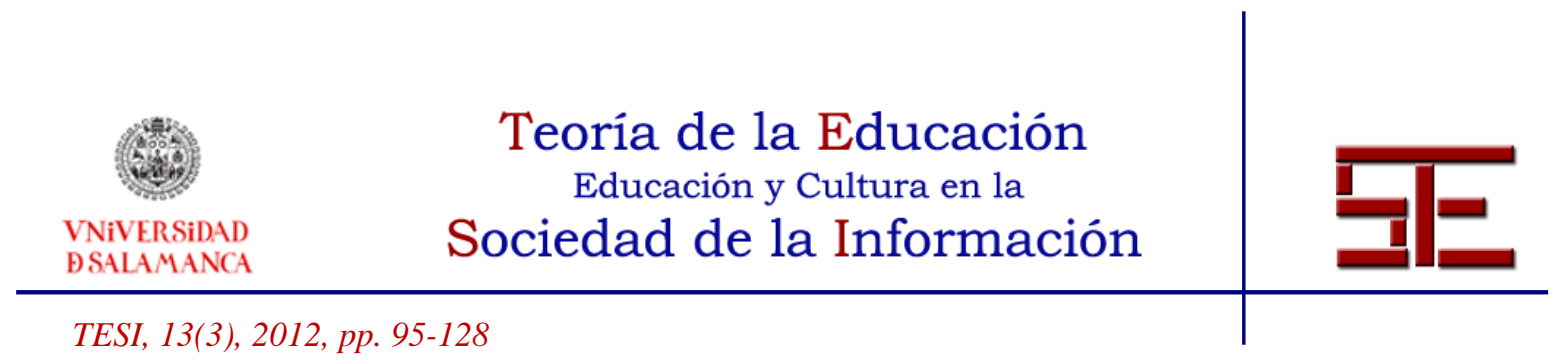

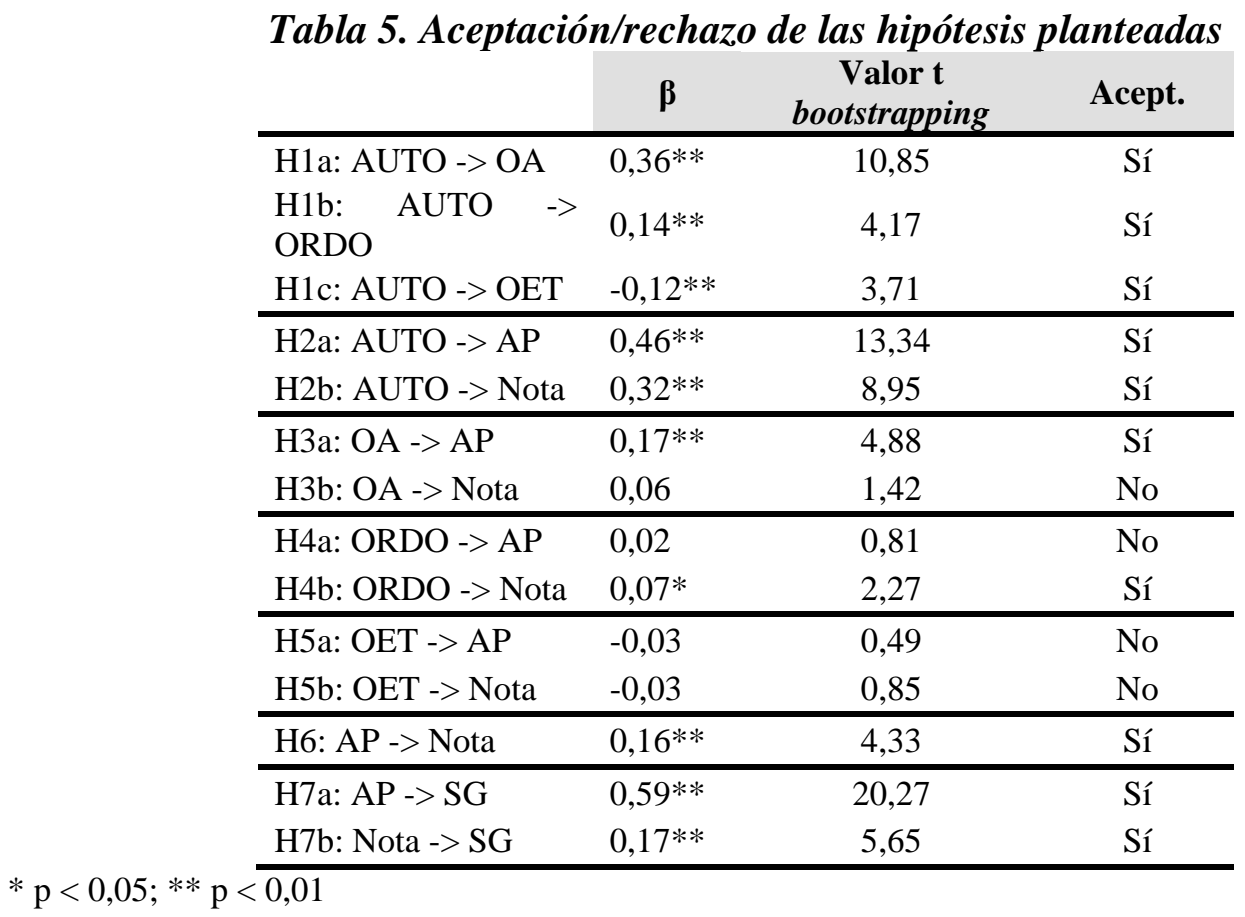

Junto a ello, los resultados muestran que el aprendizaje percibido posee un efecto positivo y significativo sobre la nota esperada (H6); así como sobre la satisfacción global del estudiante con la asignatura (H7a). Del mismo modo, la nota esperada muestra una relación positiva y significativa con dicha satisfacción $(\mathrm{H} 7 \mathrm{~b})$.

A modo de síntesis, la Tabla 5 recoge la aceptación/rechazo de las hipótesis planteadas relativas al rendiemiento académico del estudiante y sus variables endógenas.

\section{CONCLUSIONES Y LIMITACIONES}

Fruto de los resultados mostrados en el apartado anterior, son diversas las conclusiones e implicaciones que de los mismos se derivan. Ahora bien, resulta necesario subrayar que los mismos deben interpretarse en el contexto y naturaleza de la investigación realizada. Así, el ámbito de aplicación del estudio (estudiantes de una Facultad de Economía en una determinada universidad pública), limitan la posible generalización de

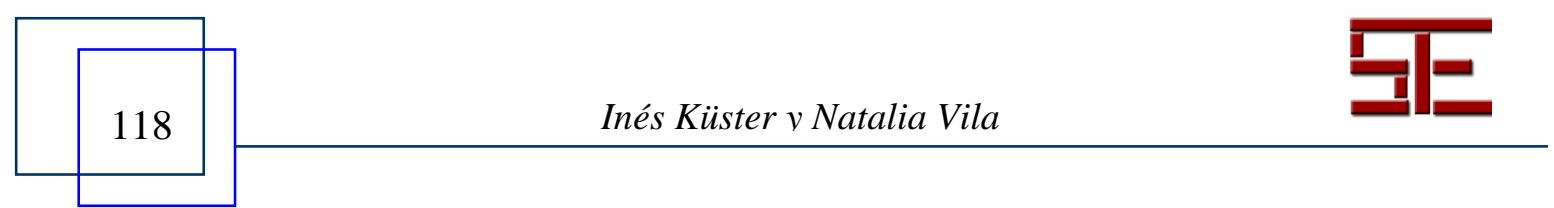




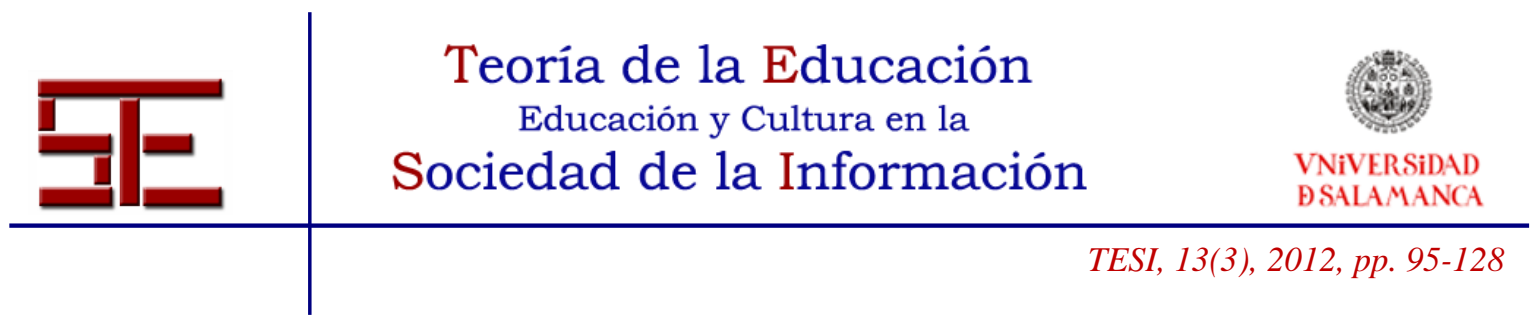

los resultados. Entendemos que la investigación realizada posee un carácter exploratorio. Se trata de una propuesta de investigación abierta. Así, con una muestra compuesta por 932 estudiantes de la Facultad de Economía de la Universidad de Valencia, los resultados del estudio nos permiten concluir los puntos que se comentan a continuación.

La investigación realizada se fundamenta en un área del sistema educativo, en una parte del proceso enseñanza-aprendizaje; la figura del estudiante. Así, se destaca el papel de la motivación del estudiante (autoeficacia y orientaciones) en su rendimiento académico esperado y en su satisfacción. En este marco, el rendimiento académico del estudiante se convierte en una pieza angular de la presente investigación. No en vano, el RD 1393/2007 establece una nueva organización de las enseñanzas universitarias que responde no sólo a un cambio estructural, sino que además impulsa un cambio en las metodologías docentes, que centra el objetivo en el proceso de aprendizaje del estudiante, en un contexto que se extiende ahora a lo largo de la vida. Desde la ley se promueven metodologías y enseñanzas orientadas hacia la autonomía del estudiante y se pretende garantizar sistemas de calidad. Es por ello que, aunque se podría haber centrado el estudio en la relación orientación al mercado del docente y rendimiento académico del estudiante, creímos necesario analizar las orientaciones y motivaciones del estudiante; así como lasmotivación del docente.

Así, se analizó el papel de la autoeficacia percibida del estudiante y de sus orientaciones (al aprendizaje, a los resultados y a evitar tareas) sobre el aprendizaje percibido y la nota esperada por el estudiante; y cómo estos influyen a su vez sobre la satisfacción global del estudiante.

Con relación al papel de la autoeficacia en la motivación y rendimiento de los estudiantes, los resultados del estudio refuerzan la premisa de partida que establece que la percepción percibida de los estudiantes es un aspecto clave para desarrollar con éxito las acciones conducentes al éxito personal (Caballero, 2006). Así, en línea con estudios previos, se ha constatado la relación positiva entre la autoeficacia y la orientación al aprendizaje; y negativa con la orientación a evitar tareas. Esto es, los estudiantes que muestran una elevada percepción de su capacidad para llevar a cabo de forma exitosa las acciones necesarias para conseguir su meta deseada estarán más motivados a aprender y, del mismo modo, menos motivados a evitar tareas.

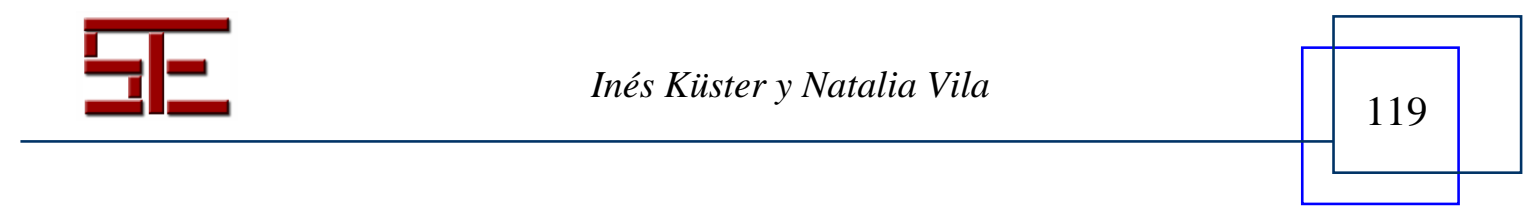




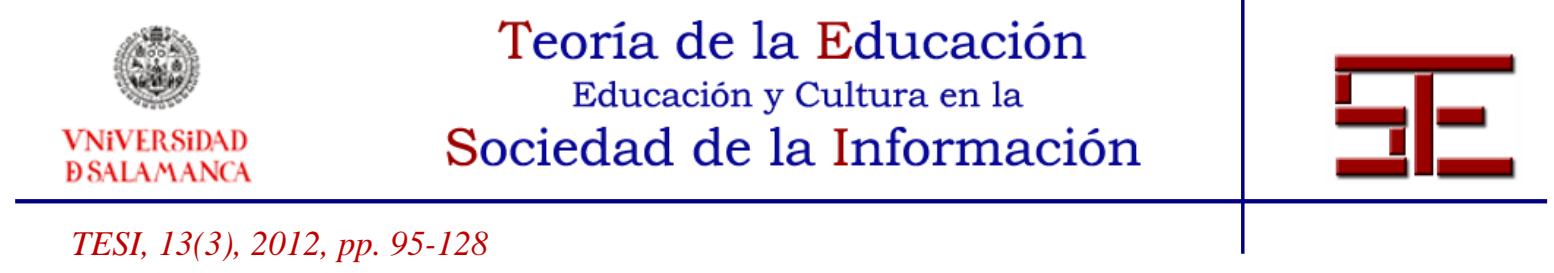

Cabe señalar que la relación entre autoeficacia y orientación al rendimiento no resultaba tan evidente en estudios previos; razón por la cual Fenollar, Román y Cuestas (2008) no la contemplaron en su estudio. Sin embargo, dicha relación ha resultado ser significativa en el presente estudio, incluso con mayor fuerza que la obtenida entre la autoeficacia y la orientación a evitar tareas. Ahora bien, y con un signo contrario al trabajo de Phillips y Gully (1997), los datos revelan que la autoeficacia del estudiante se relaciona positivamente con la orientación a los resultados. La interpretación de este resultado puede hallarse ante estudiantes competitivos; donde se presentan situaciones en las que el estudiante, con elevadas percepciones de su capacidad para llevar a buen término sus tareas, está muy motivado por alcanzar elevados y mejores resultados que sus compañeros. Situación que puede encontrarse entre estudiantes de postgrados oficiales o de titulaciones como ADE-Derecho, donde existe una elevada nota de corte, y a la que acceden estudiantes motivados tanto al aprendizaje como a los resultados altamente competitivos.

Adicionalmente, la autoeficacia se ha desvelado beneficiosa para mejorar el rendimiento académico del estudiante, en términos tanto de aprendizaje percibido como de nota esperada. En este sentido, los resultados respaldan la argumentación propuesta por Caballero (2006), en la que manifiesta que un estudiante con mayor autoeficacia tenderá a comprometerse más en las tareas asignadas y mostrará una perseverancia mayor en las mismas; y ello a pesar de las dificultades a las que se pueda encontrar. El resultado es por tanto un mayor aprendizaje y una nota esperada mayor.

Se puede concluir, por tanto, que la confianza que el estudiante tiene en sus propias capacidades le permite hacer un mejor uso de sus conocimientos y habilidades relacionados con la asignatura considerada, y por lo tanto considera que su resultado académico es mayor (Seifert y O'Keefe, 2001). Esta conclusión y lo argumentado en líneas previas es congruente con Bandura (1997), cuando afirma que quienes tienen un alto sentido de eficacia tienen capacidad para ver escenarios de éxito que les proporcionan guías y apoyos para el mejor rendimiento, mientras que los que dudan de su capacidad anticipan el fracaso o pronostican errores.

En cuanto a las orientaciones/motivaciones del estudiante, únicamente se han encontrado dos relaciones significativas. En primer lugar, la orientación o motivación al aprendizaje ha mostrado su influencia directa en el aprendizaje percibido e indirecta en la nota esperada a través del aprendizaje percibido. Así, los estudiantes preocupados por el aprendizaje obtendrán su recompensa mediante un mayor aprendizaje percibido; lo

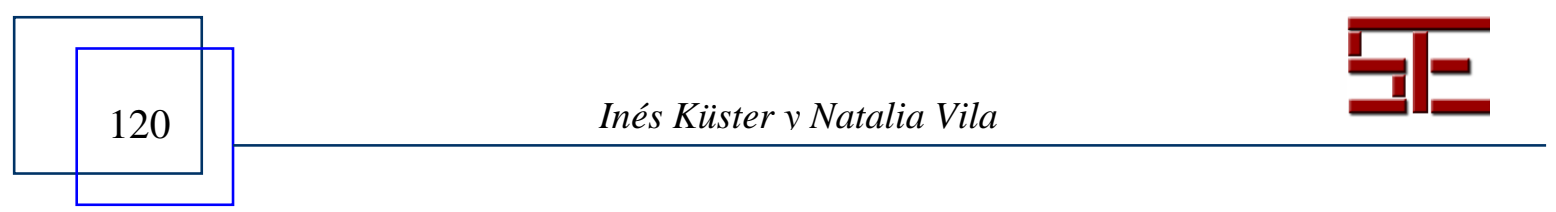




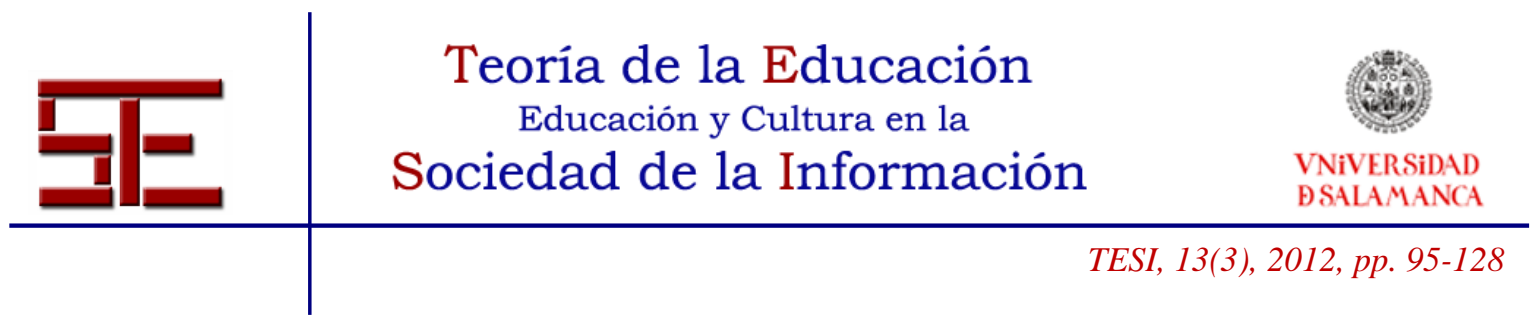

que se traducirá en una nota superior. Este resultado, similar al alcanzado por Fenollar, Román y Cuestas (2008) con estudiantes universitarios de marketing, constata por tanto la importancia de la orientación al aprendizaje a fin de conseguir que el estudiante se implique en la realización de las tareas y que se esfuerce por alcanzar determinados resultados académicos.

En segundo lugar, la orientación al resultado ha mostrado un efecto directo, positivo y significativo en la nota esperada por el estudiante; contrario a la proposición planteada. Tal y como se ha justificado anteriormente, los estudiantes que presentan dicha motivación se preocupan por ellos mismos y por cómo son percibidos por los demás; son estudiantes con una clara orientación extrínseca, más preocupados por lo que obtienen que por lo que aprenden. Así, no es de extrañar que estudiantes con una elevada orientación al resultado también esperen obtener notas más elevadas; son estudiantes con marcado carácter competitivo.

El estudio de Fenollar, Román y Cuestas (2008) no encontró ninguna relación significativa entre orientación al resultado y aprendizaje percibido, ni entre la orientación al resultado y la nota esperada. Sin embargo, tanto el estudio realizado por estos autores, como el aquí presentado, pueden concluir que la orientación al aprendizaje y la orientación al resultado no son enfoques de motivación opuestos. En esta línea, Fenollar, Román y Cuestas (2008) argumentan que si bien tradicionalmente se ha conceptualizado ambas orientaciones como opuestas, también es cierto que algunos trabajos defienden que dichos enfoques de aprendizaje pueden ser independientes, pero no relacionados de forma negativa. De acuerdo con Harackiewicz, Barron, Tauer, Carter y Elliot (2000), se trata de enfoques complementarios, consistentes con planteamientos multi-objetivo y donde ambas orientaciones pueden poseer consecuencias beneficiosas en la educación. Esto es, un individuo puede estar simultáneamente orientado al aprendizaje y al resultado (Harris, Mowen y Brown, 2005), como puede ser el caso comentado en el apartado anterior de estudiantes de la doble titulación ADE-Derecho o estudiantes que están cursando titulaciones de nivel superior (p. e. un máster oficial).

Junto a las dos orientaciones anteriores, el estudio contemplaba la orientación a evitar tareas. Sin embargo, los resultados alcanzados muestran una relación negativa con el aprendizaje percibido y la nota esperada, aunque dichas relaciones no resultaron ser significativas. Estos resultados no apoyan aquellos alcanzados por Fenollar, Román y

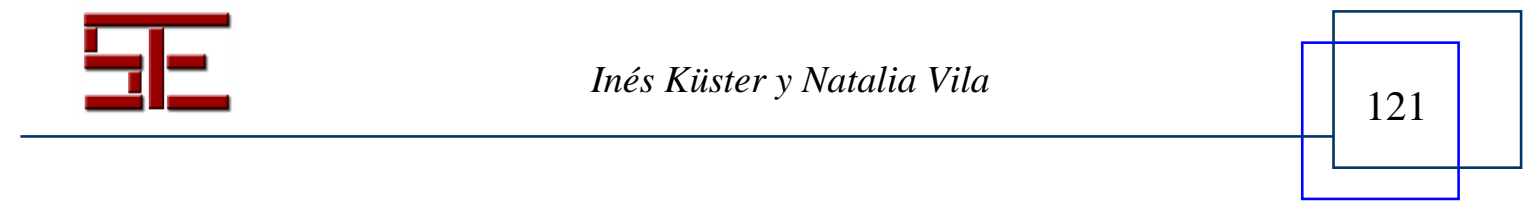




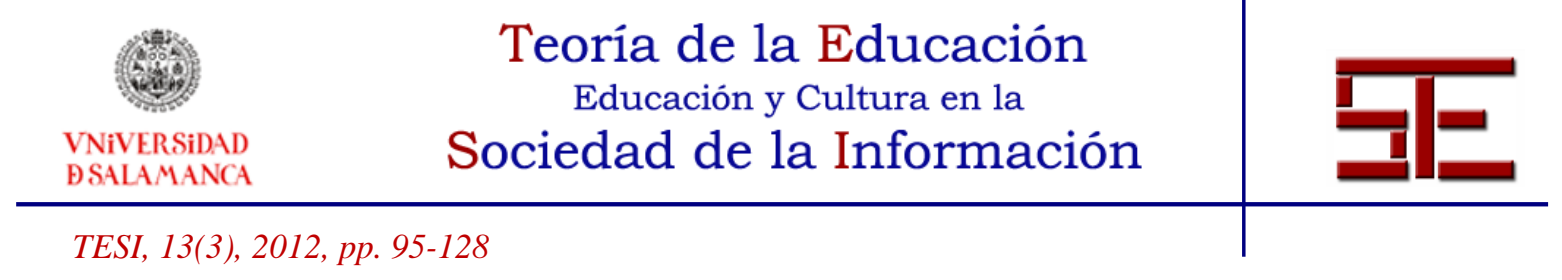

Cuestas (2008), quienes hallaron una relación directa de la orientación a evitar tareas sobre el aprendizaje percibido e indirecta sobre la nota esperada, ambas de signo negativo. La justificación de la divergencia de resultados encontrados puede encontrarse en las conclusiones del estudio llevado a cabo por Meece y Holt (1993); quienes concluyeron que dichas orientaciones no son excluyentes; esto es, un estudiante puede presentar simultáneamente dos orientaciones. Es más, la orientación a evitar tareas implícitamente puede presentarse en estudiantes con baja orientación al aprendizaje y/o con baja orientación a los resultados (Meece y Holt, 1993). Como señala Bong (2001), las orientaciones pueden ser muy distintas según los contextos de aprendizaje, dependiendo entre otros del nivel formativo y de la edad.

Finalmente, los resultados muestran que el aprendizaje percibido posee un efecto positivo y significativo sobre la nota esperada; así como sobre la satisfacción global del estudiante con la asignatura. Del mismo modo, la nota esperada muestra una relación positiva y significativa con dicha satisfacción. Así, un estudiante que sea consciente de que está aprendiendo estará más convencido de que es posible obtener una calificación mayor y ello se traducirá en una mayor satisfacción con la asignatura. Pero los resultados revelan aún algo más, simplemente el hecho de aprender puede reportar satisfacción al estudiante, con independencia de la nota que espere alcanzar.

Futuras investigaciones deberían incorporar la opinión de los estudiantes de diversas facultades y universidades, no únicamente españolas sino también europeas. De esta forma, se podría analizar si existen diferencias en el modelo del rendimiento académico del estudiante en función de su campo de estudio y de su ubicación geográfica. Adicionalmente, y tal y como se ha puesto de manifiesto al comienzo de este trabajo, resulta especialmente interesante el estudio del papel del docente en el modelo de rendimiento del estudiante.

\section{REFERENCIAS BIBLIOGRÁFICAS}

Aaker, D. A., Kumar, V. \& Day, G. S. (2001). Essential of marketing research. $2^{\text {th }}$ ed. UK: John Wiley \& Sons.

Adams, D. (1998). Examining the fabric of academic life: an analysis of three decades of research on the perceptions of Australian academics about their roles. Higher Education, 36, 421-435.

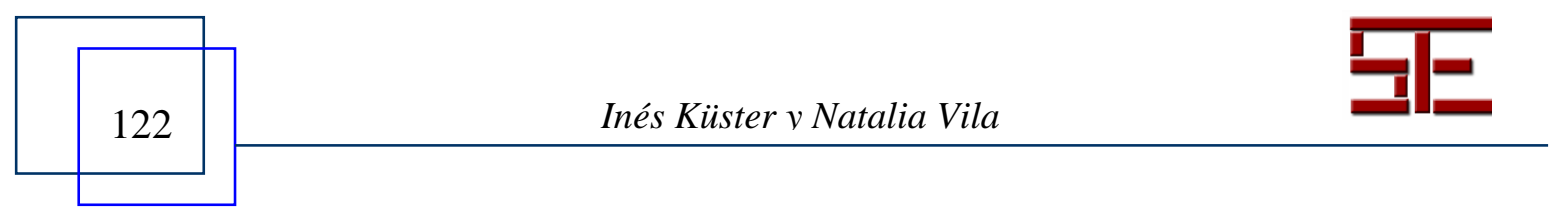




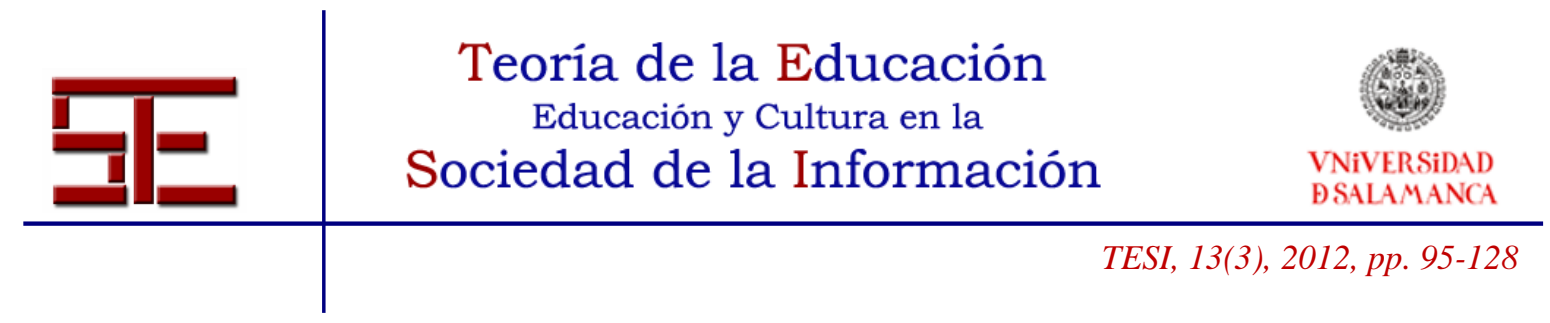

Ames, C. (1992). Classrooms: Goals, Structures, and Student Motivation. Journal of Educational Psychology, 84 (3), 261-271.

Bandura, A. (1986). Social foundations of thought and action: a social cognitive theory. Englewood Cliffs, NJ: Prentice-Hall.

Barclay, D., Higgins, C. \& Thompson, R. (1995). The partial least squares (PLS) approach to causal modelling. Technology Studies, 2 (2), 285-309.

Bong, M. (2001). Role of self-efficacy and task-value in predicting college students' course performance and future enrollment intentions. Contemporary Educational Psychology, 26, 553-570

Caballero, C. (2006). Burnout, engagement y rendimiento académico entre estudiantes universitarios que trabajan y aquellos que no trabajan. Revista Psicogente, 9 (16), 11 27.

Caballero, C., Abello, R. \& Palacio, J. (2007). Relación del burnout y el rendimiento académico con la satisfacción frente a los estudios en estudiantes universitarios. Avances en Psicología Latinoamericana, 25 (2), 11-27.

Carmines, E. G. \& Zeller, R. A. (1979). Reliability and validity assessment. Sage University Paper Series on Quantitative Applications in the Social Sciences, 07-017. Beverly Hills, CA: Sage.

Cattaneo, M. E., Huertas, J. A. \& De la Cruz, M. (2004). ¿Qué dicen los estudiantes de nivel medio y de grupos sociales distintos acerca de sus metas para el aprendizaje?. Estudios Pedagógicos (30), 21-37.

Cepeda, G. \& Roldán, J. L. (2004). Aplicando en la práctica la técnica PLS en la administración de empresas. XIV Congreso Asociación Científica de Economía y Dirección de la Empresa (ACEDE). Murcia.

Church, M. A., Elliot, A.J., \& Gable, S.L. (2001). Perceptions of classroom environment, achievement goals, and achievement outcomes. Journal of Educational Psychology, 93 (1), 43-54.

Dupeyrat, C., \& Mariné, C. (2005). Implicit of intelligence, goal orientation, cognitive engagement, and achievement: A test of Dweck's model with returning to school adults. Contemporary Educational Psychology, 30, 43-59.

Dweck, C.S. (1986). Motivational Processes Affecting Learning. American Psychologist, 41 (21), 1040-1048.

Elliot, E. \& Dweck, C (1988). Goals: an approach to motivation and achievement. Journal of Personality and Social Psychology, 54, 5-12.

Elliot, A. J., McGregor, H. A. \& Gable, S. (1999). Achievement goals, study strategies, and exam performance: A Mediational Analysis. Journal of Educational Psychology, $91(3), 549-563$.

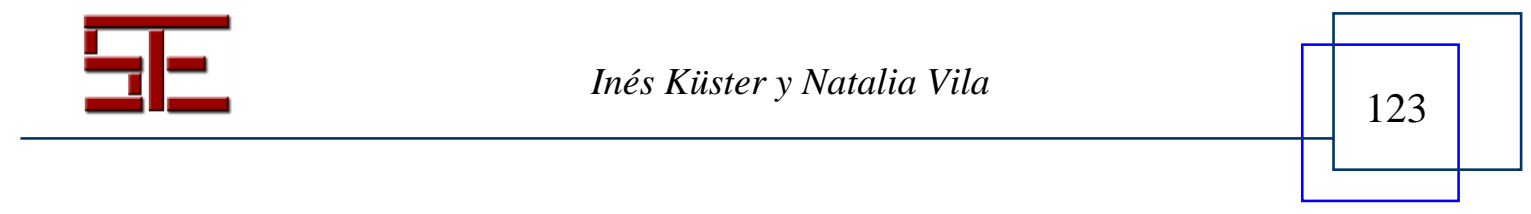




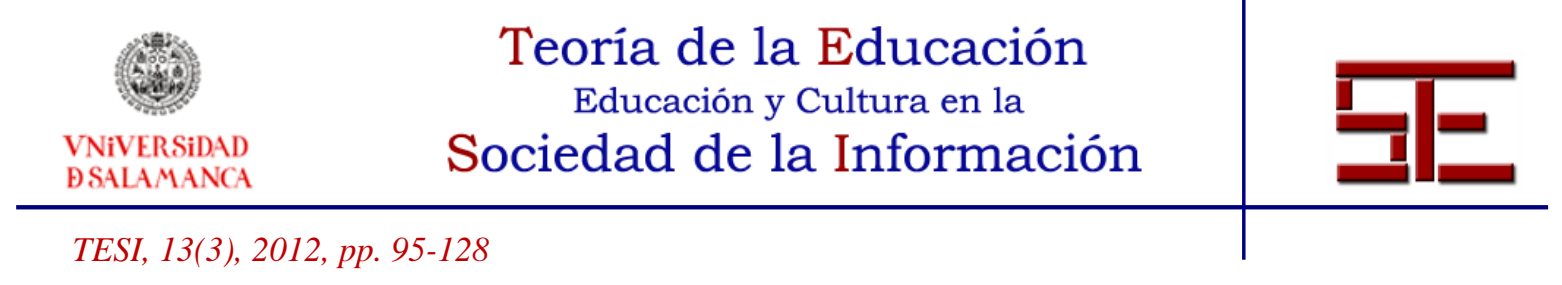

Elliot, A. J., Shell, M. M., Henry, K. B. \& Maier, M. A. (2005). Achievement goals, performance contingencies, and performance attainment: an experimental test. Journal of Educational Psychology, 97 (4), 430-440.

Fenollar, P., Cuestas, P. J. \& Román, S. (2007). University students' academic performance: An integrative conceptual framework and empirical analysis. British Journal of Educational Psychology, 77, 873-891.

- (2008). "Antecedentes del rendimiento académico: aplicación a la docencia en marketing". Revista Española de Investigación de Marketing, 12 (2), 7-24.

Flavián, C. \& Lozano, F. J. (2004). Influencia de los moderadores ambientales en la relación entre orientación al entorno y resultado. Un análisis con regresiones moderadas en el ámbito educativo. Revista Española de Investigación de Marketing ESIC, 8 (2), 123-153.

- (2005a). Influencia de la actitud orientada al mercado del profesorado universitario sobre su comportamiento. Revista Europea de Dirección y Economía de la Empresa, 14 (1), 123-140.

- (2005b). Relación entre orientación al mercado y resultados en el sistema público de educación. Revista Asturiana de Economía, RAE (32), 69-93.

Fornell, C. \& Larcker, D.F. (1981). Evaluating structural models with unobservable variables and measurement error. Journal of Marketing Research, 28, 39-50.

Fredericksen, E., Pickett, A., Shea, P., Pelz, W. \& Swan, K. (1999). Students satisfaction and perceived learning with online courses. Proceedings Sloan Summer Workshop on Asynchronous Learning Networks, 7-36.

García, C. R. \& Fernández, F. J. C. (2002). La orientación de la universidad hacia la empresa y la sociedad: evaluación de la calidad universitaria. ESIC MARKET (111), 9-24.

Gao, Z. \& Xiang, P. (2007). Exploring the Mediating Effect of Self-Efficacy on the Relationships Between Achievement Goals and Fitness Testing Scores Among Secondary Physical Education Students. 2007 AAHPERD National Convention and Exposition, March 13 -- 17, Baltimore, MD.

Greene, B.A. \& Miller, R.B. (1996): "Influences on archievement: goals, perceived ability, and cognitive engagement", Contemporary Educational Psychology, 21, 181192.

Greene,B. A., Miller, R. B., Crowson, H. M., Duke, B. L. \& Akey, K. L. (2004). Predicting high school students' cognitive engagement and achievement: contributions of classroom perceptions and motivation. Contemporary Educational Psychology, 29, 462-482.

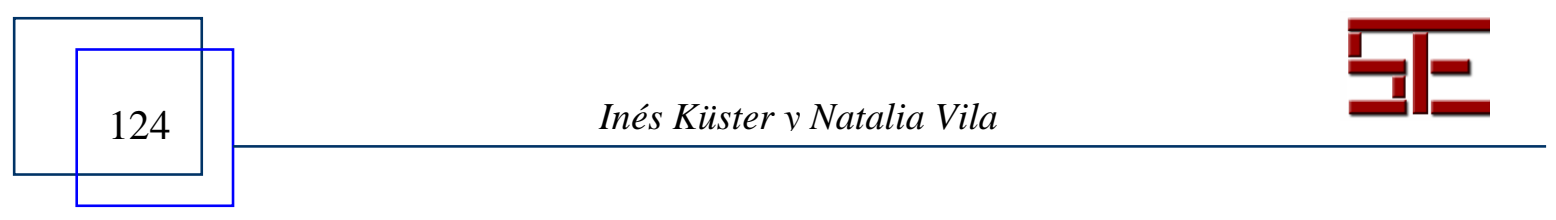




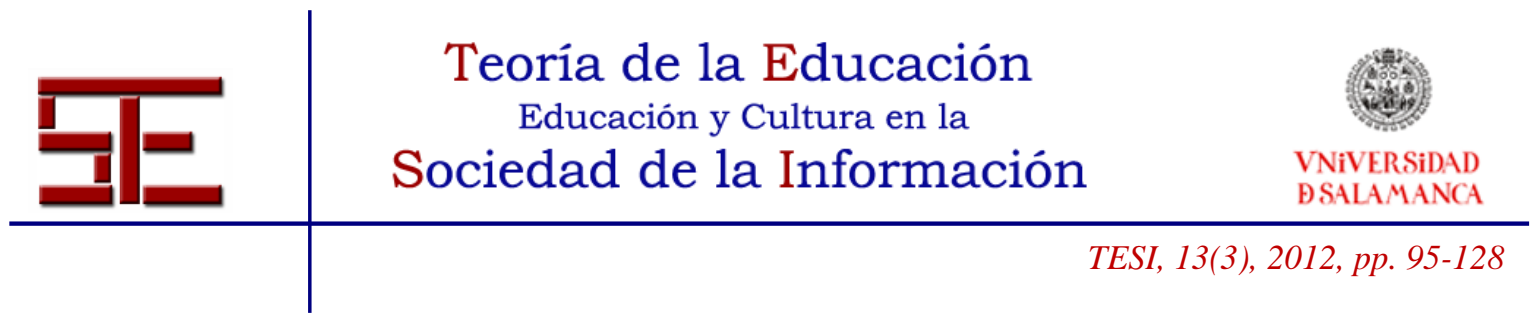

Gullason, E. T. (2009). A compilation and synthesis of effective teaching strategies in the economics discipline. Journal of Business \& Economic Studies, 15 (2), 83-105.

Hair, J. F. Black, W. C. Babin, B. J., Anderson, R. E. \& Tatham, R. L. (2006). SEM: confirmatory factor analysis. Multivariata data analysis. Upper Saddle River, NJ: Pearson Education Inc.

Harackiewicz, J. M., Barron, K. E., Tauer, J. M., Carter, S. M. \& Elliot, A. J. (2000). Short-term and long-term consequences of achievement goals: predicting interest and performance over time. Journal of Educational Psychology. 92 (2), 316-330.

Harris, E. G., Mowen, J. C. \& Brown; T. J. (2005). "Re-examining salesperson goal orientations: personality influencers, customer orientation, and work satisfaction. Journal of the Academy of Marketing Science, 33 (1), 19-35.

Houston, F. S. (1986): "The marketing concept: what it is and what it is not". Journal of Marketing, 50 (2), 23-39.

Joo, Y.J., Bong, M. \& Choi, H. J. (2000). Self-efficacy for self-regulated learning, academic self-Efficacy in Web-based instruction. Educational technology, Research and Development, 48 (2), 5-17.

Kaplan, A. \& Maehr, M. L. (1999) Achievement Goals and Student Well-Being. Contemporary Educational Psychology, 24, 330-358.

Kinnear, T. C. \& Taylor, J. R. (1991). Marketing research: and applied approach. $4^{\circ}$ ed. New York: McGraw Hill.

Lawson-Body, A. \& O'Keefe, T. P. O. (2006) Interorganizational Relationships in the Context of SMEs' B2B E-Commerce. Journal of Electronic Commerce in Organizations, 4 (4), 1-28.

Malhotra, N. \& Birks, D. (2007). Marketing Research: an applied approach: 3rd European Edition, Harlow, UK, Pearson Education.

Marks, R. B. (2000). Determinants of Student Evaluations of Global Measures of Instructor and Course Value. Journal of Marketing Education, 22 (2), 108-119.

Marsh, H. W. (1987). Student evaluations of university teaching: research findings, methodological issues, and directions for future research. International Journal of Educational Research, 11 (3), 253-388.

Marsh, H.W. \& Hocevar, D. (1991). Students' evaluations of teaching effectiveness: the stability of mean ratings of the same teachers over a 13-year period. Teaching \& Teacher Education, 7 (4), 303-314.

Meece, J. L. \& Holt, K. (1993). A pattern analysis of students' achievement goals. Journal of Educational Psychology, 85 (4), 582-590.

Michavila, F. (2008). ¿Soplan vientos de cambio universitarios?. Revista de Docencia Universitaria, 1 (1).

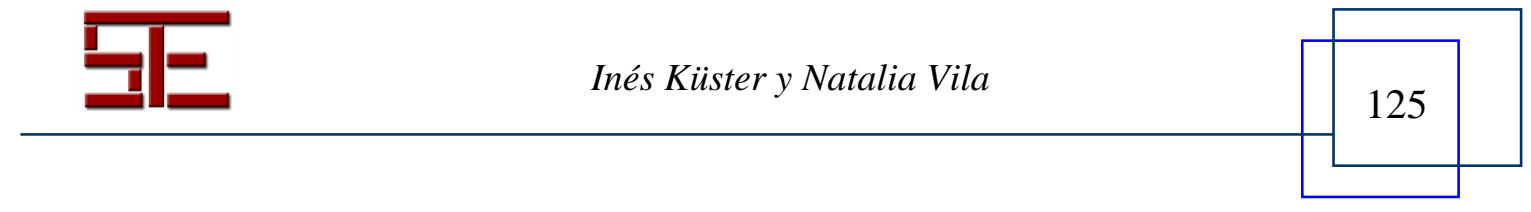




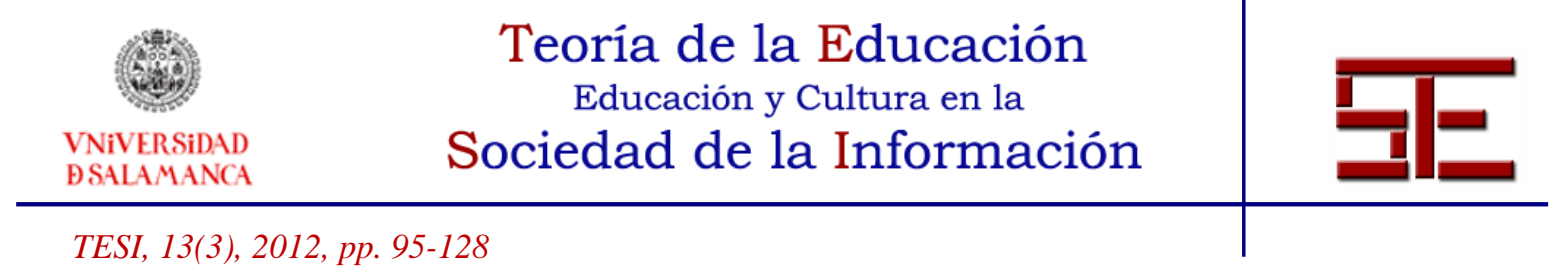

Midgley C., Kaplan, A., Middleton, M., Maehr, M.L., Urdan, T., Anderman, L. H., Anderman, E. \& Roeser, R. (1998). The development and validation of scales assessing students' achievement goal orientations. Contemporary Educational Psychology, 23, 113-131.

Miller, R. B., Behrens, J. T., Greene, B. A. \& Newman, D. (1993). Goals and perceived ability: impact on students valuing, self-regulation, and persistence. Contemporary Educational Psychology, 18, 2-14.

Murphy P. K. \& Alexander, P. A. (2000). A Motivated Exploration of Motivation Terminology. Contemporary Educational Psychology, 25, 3-53.

Nurmi, J. E., Onatsu, T. \& Haavisto, T. (1995). Underachievers' cognitive and behavioral strategiess-self-handicapping at school. Contemporary Educational Psychology, 20, 188-200.

Olivares, O. J. (2001). Student interest, grading leniency, and teacher ratings: a conceptual analysis. Contemporary Educational Psychology, 26, 382-399.

Pajares, F. (1996). Self-efficacy beliefs in academic settings. Review of Educational Research, 66 (4), 543-578.

Pajares, F., Hartley, J. \& Valiante, G. (2001). Response format in writing self-efficacy assessment: greater discrimination increases prediction. Measurement and Evaluation in Counseling and Development, 33 (4), 214-221.

Pajares, F. \& Kranzler, J. (1995). Self-efficacy beliefs and general mental ability in mathematical problem-solving. Contemporary Educational Psychology, 20, 426443.

Petruzzellis, L., D’Uggento, A. M. \& Romanazzi, S. (2006). Students satisfaction and quality of service in Italian universities. Managing Service Quality, 16 (4), 349-364.

Phillips, J.M. \& Gully, S.M. (1997). Role of goal orientation, ability, need for achievement, and locus of control in the self-efficacy and goal--setting process. Journal of Applied Psychology, 82 (5), 792-802.

Prieto Navarro, L. (2001). La autoeficacia en el contexto académico: exploración bibliográfica comentada. Miscelánea Comillas, 59, 281-292.

Real Decreto 1393/2007, de 29 de octubre, por el que se establece la ordenación de las enseñanzas universitarias oficiales. Publicado en BOE n. 260 de 30 de octubre de 2007.

Ringle, C., Wende, S. \& Alexander, W. (2005). SmartPLS 2.0 (beta). http://www.smartpls.de. University of Hamburg, Hamburg, Germany.

Ross, C. E. \& Broh, B. A. (2000). The Roles of Self-esteem and the Sense of Personal Control in the Academic Achievement Process. Sociology of Education, 73 (4), 270284.

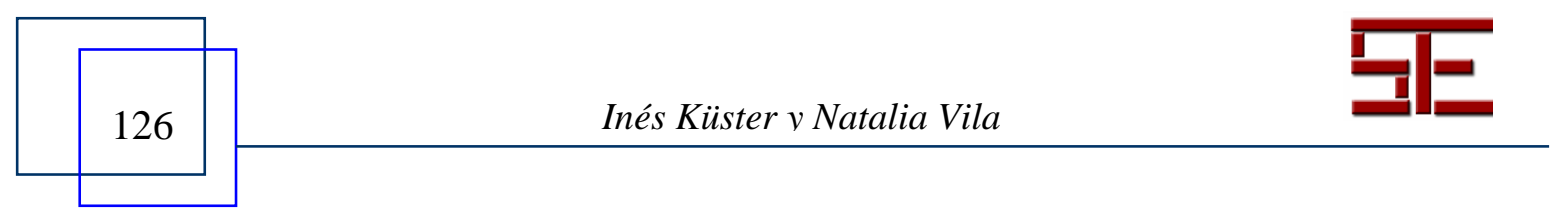




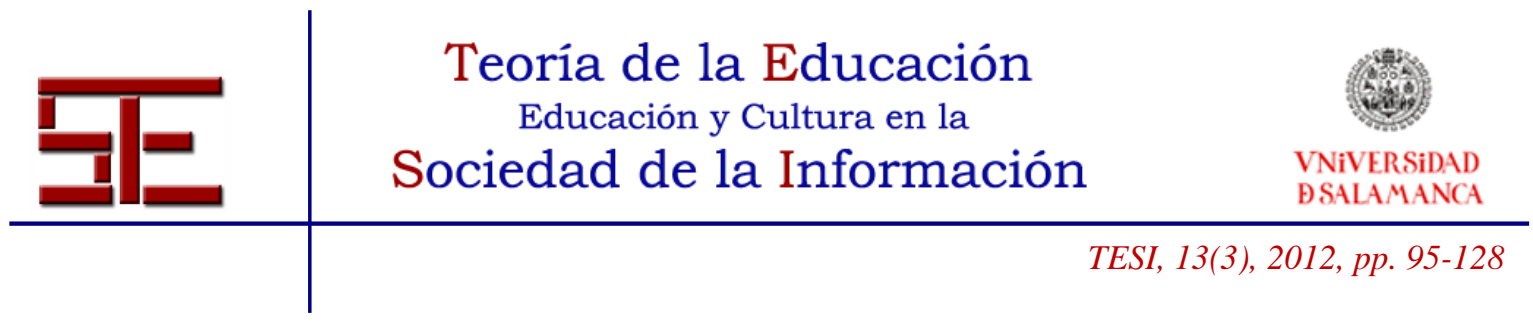

Sánchez-Franco, M. J. \& Roldán, J. L. (2005). Web acceptance and usage model: A comparison between goal-directed and experiential web users. Internet Research; 15 $(1 ; 21-48$.

Schiefele, U. (1991). Interest, learning, and motivation. Educational Psychologist, 26 (3/4), 299-323.

Seifert, T. L. \& O'Keefe, B. A. (2001). The relationship of work avoidance and learning goals to perceived competence, externality and meaning. British Journal of Educational Psychology, 71, 81-92.

Skaalvik, E. M. (1997). Self-enhancing and self-defeating ego orientation: relations with task and avoidance orientation, achievement, self-perceptions, and anxiety. Journal of Educational Psychology, 89 (1), 71-81.

Smith, L., Sinclair, K. E. \& Chapman, E. S. (2002). Student's goals, self-efficacy, selfhandicapping, and negative affective responses: an Australian senior school student study. Contemporary Education Psychology, 27, 471-485.

Sullivan, J. R., Guerra, N.S., \& Hsieh, P. (2007). A closer look at college students: selfefficacy and goal orientation. Journal of advanced academics, 18 (3), 454-476.

Tejedor, F. J. \& García-Valcárcel, A. (2007). Causas del bajo rendimiento del estudiante universitario (en opinión de los profesores y alumnos). Propuestas de mejora en el marco del EEES. Revista de Educación (342), 443-473.

Tiebout, C. M. (1956). The pure theory of local expenditures. Journal of Political Economy. 64, 416-424.

Usher, E.L. \& F. Pajares (2006). Sources of academic and self-regulatory efficacy beliefs of entering middle school students. Contemporary Educational Psychology, 31, 125-141.

Valle, A., Cabanach, R.G., Núnez, J.C., González-Pienda, J., Rodríguez, S. \& Piñeiro, I. (2003). Multiple goals, motivation and academic learning. British Journal of Educational Psychology, 73, 71-87.

Vermetten, Y.J., Lodewijks, H. G. \& Vermunt, J. D. (2001). The Role of Personality Traits and Goal Orientations in Strategy Use. Contemporary Educational Psychology, 26, 149-170.

Zikmund, W. G. (2003). Fundamentos de investigación de mercados. Madrid: Paraninfo.

Zimmerman, B. J. (2000). Self-Efficacy: An Essential Motive to Learn. Contemporary Educational Psychology, 25, 82-91.

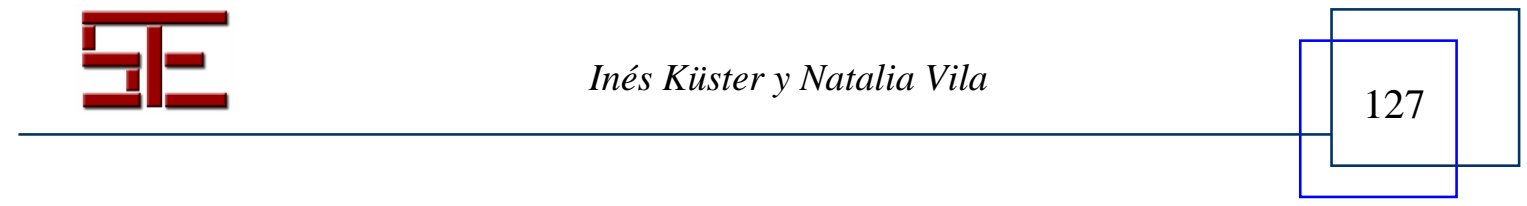




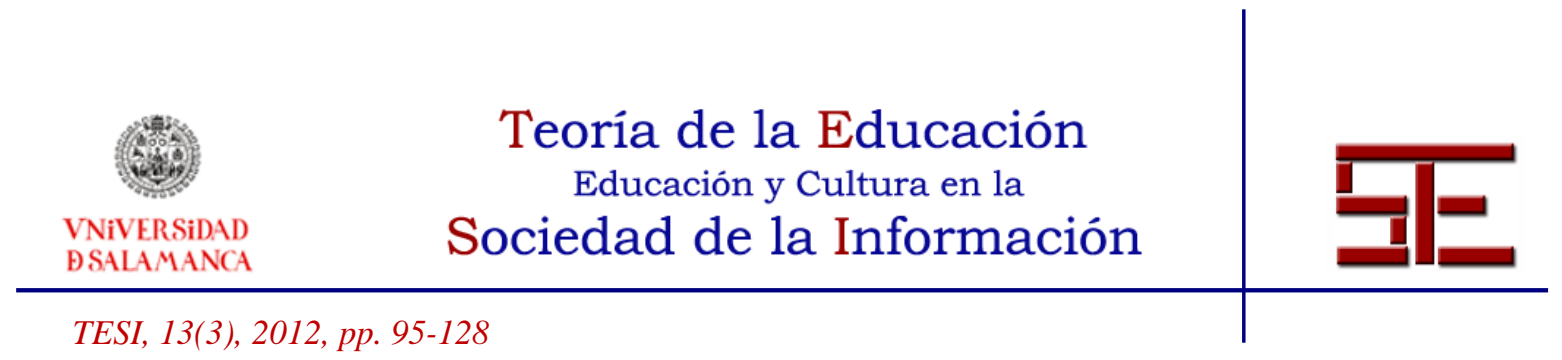

Para citar el presente artículo puede utilizar la siguiente referencia:

Küster, I. y Vila, N. (2012). El modelo del rendimiento académico del estudiante universitario: aplicación a una facultad de economía. Revista Teoría de la Educación: Educación y Cultura en la Sociedad de la Información. 13(3), 95-127 [Fecha de consulta: dd/mm/aaaa].

http://campus.usal.es/ revistas_trabajo/index.php/revistatesi/article/view/9133/9366

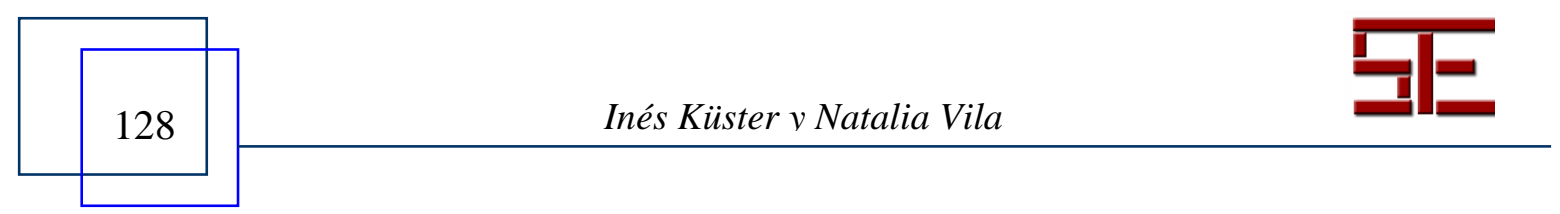

